\title{
Future Projections of Extreme Ocean Wave Climates and the Relation to Tropical Cyclones: Ensemble Experiments of MRI-AGCM3.2H*
}

\author{
Tomoya Shimura, Nobuhito Mori, And Hajime Mase \\ Disaster Prevention Research Institute, Kyoto University, Kyoto, Japan
}

(Manuscript received 18 October 2014, in final form 15 September 2015)

\begin{abstract}
Future projections of extreme ocean surface wave climates were carried out with single-model ensemble experiments of the atmospheric global climate model MRI-AGCM3.2H. The ensemble experiments of MRIAGCM3.2H consist of four future sea surface temperature (SST) ensembles and three perturbed physics (PP) ensembles. This study showed that future changes in extreme wave heights strongly depend on the global climate model (GCM) performance to simulate tropical cyclones (TCs), indicating a need to acknowledge that results in a study that employs a low-performance model are not able to account for extreme waves associated with TCs (TC waves). The spatial distribution of future changes in non-TC extreme wave heights on the global scale was similar to that for mean wave heights; namely, wave heights increase over the middleto-high latitudes in the Southern Ocean and central North Pacific and decrease over midlatitudes and the North Atlantic, although the magnitude of future changes for extreme wave heights is greater than for mean wave heights. The variance of future changes mainly depends on differences in physics among PP ensemble experiments rather than differences in SST ensembles. The 10-yr return wave heights of TC waves over the western North Pacific showed either an increase or a decrease of $30 \%$ for different regions, maximally. The spatial distribution of future changes in TC waves can be explained by an eastward shift of TC tracks.
\end{abstract}

\section{Introduction}

Climate change impacts are a great concern to sustainable social development. The number of studies assessing the long-term change in oceanographic phenomena (especially the impact on sea level rise) resulting from climate change has been increasing. Ocean surface gravity waves are a key consideration for beach morphology, coastal disaster planning, offshore industry, and ship navigation. Thus, changes in the ocean wave climate, especially extreme wave climate, have significant impacts on many industries. The extreme wave climate is changing at a faster rate than the mean climate has in the past (Ruggiero et al. 2010; Young et al. 2011, 2012). The extreme wave climate variability and

\footnotetext{
* Supplemental information related to this paper is available at the Journals Online website: http://dx.doi.org/10.1175/JCLI-D-1400711.s1.

Corresponding author address: Tomoya Shimura, Disaster Prevention Research Institute, Kyoto University, Gokasho, Uji, Kyoto 611-0011, Japan.

E-mail: shimura@storm.dpri.kyoto-u.ac.jp
}

trend can be generally determined by extratropical and tropical storm activity. The positive trends of extreme wave heights over the past 50 years are due to changes in extratropical storm characteristics, such as intensification and/or track shifts; these trends have been reported for the North Pacific (Bromirski et al. 2013; Menéndez et al. 2008; Graham and Diaz 2001), the northeastern North Atlantic (Wang et al. 2009; Wang and Swail 2001), and the Southern Ocean (Hemer 2010; Sterl and Caires 2005). Emanuel (2005) showed that, since the mid-1970s, tropical cyclones have become increasingly destructive because of longer storm duration and greater intensity. Sasaki et al. (2005) and Yong et al. (2008) indicated that summertime extreme wave heights have increased in the western North Pacific during recent years resulting from intense tropical cyclones. Furthermore, extreme hurricane-generated waves in the western North Atlantic have also increased (Komar and Allan 2008; Bromirski and Kossin 2008), and Moore et al. (2013) concluded that coastline changes to the U.S. East Coast were attributed to changes in hurricane-generated waves. Slott et al. (2006) indicated that coastline changes resulting from storm pattern and wave climate changes can be comparable to the effects of sea level rise. 
Dynamic projections of future wave climates under greenhouse gas emission scenarios have been performed (e.g., Mori et al. 2010; Hemer et al. 2013). IPCC (2013, chapter 13) summarized current understandings on "mean" future wave climate projections under greenhouse gas emission scenarios, which showed common features of global wave climate changes, such as increased mean wave heights in the Southern Ocean associated with enhanced surface wind speeds in the future. However, in general, wave climate projections have uncertainty associated with them. Shimura et al. (2015) analyzed the uncertainty in the projected future changes of mean wave heights in the western North Pacific and concluded that the uncertainty strongly depends on the uncertainty in future equatorial sea surface temperatures (SST) and typhoon characteristics. Fan et al. (2013) investigated the sensitivity of future changes in wave heights to $\mathrm{CO}_{2}$ and ozone in addition to SST. Although the impacts of global climate change on mean wave climate are being unveiled, the extreme wave climate effects are less understood than the mean ones. Therefore, our study examines extreme wave climate change.

Fan et al. (2013) and Wang et al. (2014) showed future changes in defined extreme wave heights, which are represented as $99 \%$ nonexceedance probability wave heights (Fan et al. 2013) and 10-yr return level wave heights (and annual maximum) (Wang et al. 2014). Fan et al. (2013) concluded that changes in extreme wave heights are mainly dominated by the changes in tropical cyclones, and that those changes have large uncertainties. However, Wang et al. (2014) did not mention the effects of tropical cyclones and the future changes in extreme wave heights resulting from tropical cyclones; these effects and changes are clearly seen in Fan et al. (2013) and cannot be detected explicitly from the results of Wang et al. (2014).

The prior work of Wang and Swail (2006) indicated that projected changes in extreme wave heights were consistent with changes in extratropical cyclones. The differences between Fan et al. (2013) and Wang et al. (2014) can be attributed to model performance to simulate tropical cyclones; the simulations of Fan et al. (2013) used a high-resolution atmospheric global climate model (AGCM) that can produce tropical cyclone properties relatively well. On the other hand, Wang et al. (2014) used a relatively low-resolution global climate model (GCM) that cannot simulate strong tropical cyclones. Therefore, irrespective of the accuracy of the wave model, it is not reasonable to compare extreme wave climate change results between outputs with lowand high-resolution climate simulations, because the dominant causes of extreme wave climate changes are different between them. To compare the results with various other models, we will analyze the extreme wave climate change by separating the wave contributions into two groups: tropical cyclone-generated waves and nontropical cyclone-generated (especially extratropical cyclone) waves. This separation will improve our understanding of the mechanisms contributing to future wave climate changes.

The objectives of this study are to project extreme wave climates and to investigate the contributions of tropical cyclone changes to extreme wave climate changes separately from nontropical cyclone changes. We will focus on tropical cyclones in the western North Pacific (WNP), which is the most active tropical cyclone (TC) region, and on nontropical cyclones (non-TC) over the entire global domain.

\section{Methodology}

Wave climate projection data used in this study are the same as those in Shimura et al. (2015), who studied the future changes in mean wave height. The methodology of wave climate projection is briefly described in the following subsection and then the methodology of extreme wave analysis is shown.

\section{a. Wave climate projection}

Global wave climate projection can be described with the following three steps.

1) Global climate simulation by an atmosphere-ocean coupled general circulation model (AOGCM) under an emissions scenario.

2) Global atmospheric climate simulation by an AGCM using SST data from the AOGCM as a boundary condition.

3) Global wave simulation by a wave model forced with the sea surface winds of the AGCM.

The AGCM used in this study was developed by the Japanese Meteorological Research Institute (MRI), the MRI-AGCM3.2H (Mizuta et al. 2012). The spatial resolution is about $60-\mathrm{km}$ mesh. The SST and perturbed physics (PP) ensemble experiments were carried out with MRI-AGCM3.2H, using four different future SST conditions and three different cumulus convection schemes: Yoshimura (YS), the prognostic ArakawaSchubert (AS), and Kain-Fritsch (KF). One of the SST conditions is the ensemble mean SST projected by 18 AOGCMs from phase 3 of the Coupled Model Intercomparison Project (CMIP3; Meehl et al. 2007) under the Special Report on Emissions Scenarios (SRES) A1B scenario. The other three SST conditions are differently classified SST patterns derived from 18 CMIP3 model simulations by employing cluster analysis. The four 
different SST conditions are denoted as clusters 0-3 (c0-c3), where $\mathrm{c} 0$ indicates the mean of the 18 CMIP3 models. The details of these ensemble experiments with MRI-AGCM3.2H are described in Murakami et al. (2012), Endo et al. (2012), and Shimura et al. (2015).

Global wave climate projection was carried out with WAVEWATCH III, version 3.14 (Tolman 2009), forced by sea surface winds from MRI-AGCM3.2H. The global domain was set for the latitudinal range of $90^{\circ} \mathrm{S}-67^{\circ} \mathrm{N}$ over all longitudes with $1^{\circ} \times 1^{\circ}$ spatial grids. Directional resolution is $15^{\circ}$, and the frequency is from 0.04 to $0.5 \mathrm{~Hz}$ with discretization in 25 increments logarithmically as a conventional setup. Sea ice is not considered in this simulation. The Tolman and Chalikov (1996) source term package without a capped drag coefficient was used for wind input and dissipation. The nesting in the WNP $\left(11^{\circ}-\right.$ $50^{\circ} \mathrm{N}, 121^{\circ}-160^{\circ} \mathrm{E}$ ) was performed with $0.5^{\circ}$ latitudelongitude spatial resolution and $10^{\circ}$ directional resolution. Six-hourly winds were linearly interpolated to 1-hourly winds for global wave climate simulation and 30-min winds for WNP wave simulation. Data from the $1^{\circ}$ resolution global wave simulation were used for analysis on non-TC waves, and data from the $0.5^{\circ}$ resolution WNP wave climate simulation were used for analysis on TC waves.

The present climate was defined as 1979-2003, and the future climate is defined as 2075-99. The three present climate experiments (HPA) with three cumulus convection schemes-YS, AS, and $\mathrm{KF}$ - are denoted as HPA_YS, HPA_AS, and HPA_KF, respectively. The 12 future climate experiments (HFA) with three cumulus convection schemes and four future SST conditions are denoted as HFA_ $\left\{\mathrm{YS}, \mathrm{AS}_{1} \mathrm{KF}\right\}_{-}\{\mathrm{c} 0, \mathrm{c} 1, \mathrm{c} 2, \mathrm{c} 3\}$ (e.g., HFA_YS_c0). The results of the mean wave climate changes with this wave climate projection are described in Shimura et al. (2015).

\section{b. Extreme wave analysis}

Extreme waves generated by TC and non-TC events were separated; this separation requires TC track data. Murakami et al. (2012) detected TCs in MRI-AGCM3.2H simulations using an objective TC detection method. Their TC detection method employed five criteria: 1) relative vorticity at $850 \mathrm{hPa}, 2)$ temperature anomaly in the warmcore region, 3) maximum wind velocity at $850 \mathrm{hPa}, 4$ ) maximum wind velocity at $300 \mathrm{hPa}$, and 5) cyclone duration. The total number of TC genesis was controlled by changing the criteria thresholds. The TC data extracted by Murakami et al. (2012) were used in this study.

\section{1) Non-TC waves}

To identify non-TC waves, waves in a moving $20^{\circ} \times$ $20^{\circ}$ box surrounding the TC center were eliminated from the original wave data. Although the definition of box
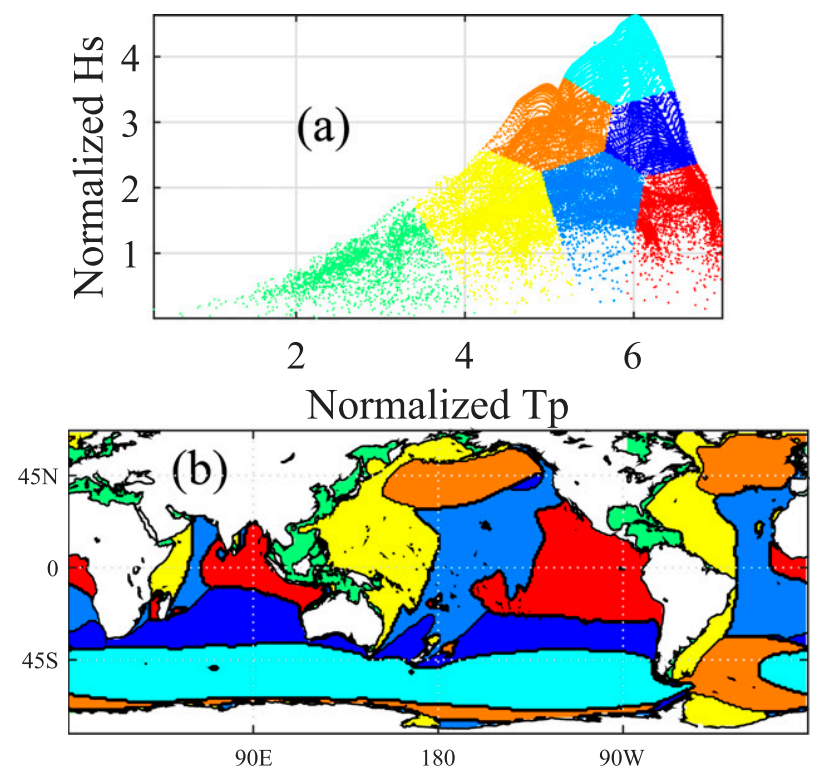

FIG. 1. Classification of mean wave climate. (a) Relationship between mean significant wave height and period at each grid point. All values are normalized by the standard deviation. (b) The global map with colors corresponding to the relationship colorcoded in (a).

size is arbitrary, the results are not sensitive to the size of box if the size of box is large enough in comparison with the size of atmospheric disturbance. Regional frequency analysis was applied to non-TC events; a homogeneous region of wave climate characteristics surrounding the target grid point was defined and all the wave data in the homogeneous region were used as data for the target grid point. The definition of a homogeneous region is as follows.

(i) A region within $G$ kilometers of the target point in longitude-latitude geophysical space; $G=500 \mathrm{~km}$ in this study, based on the synoptic scale.

(ii) A region within $C$ units of the target point in wave height-wave period climatological space (Cooley et al. 2007). Figure 1a shows the relationship between climatological value (mean value in $25 \mathrm{yr}$ ) of significant wave height and peak wave period at each grid point over the global domain (the values were normalized by standard deviation). Figure $1 \mathrm{~b}$ shows the global map with colors corresponding to the relationship color-coded in Fig. 1a (note that Fig. 1 is based on the HPA_YS experiment for example). The relationship shown in Fig. 1 can identify the characteristics of each region, such as semiclosed ocean, wind-wave- or swell-dominated ocean, swellsheltered ocean, and so on. This relationship is a useful criterion to define a homogeneous region. The criterion that the distance in Fig. 1a is less than or equal to $0.5(C \leq 0.5)$ is used in this study. We 
confirmed that this criterion $(C \leq 0.5)$ is effective at correctly classifying ocean regions across landmasses and ocean areas apart from land.

(iii) The discordancy measure $D$ is less than 3 (Hosking and Wallis 1997). Term $D$ is defined as the difference in $L$-moment ratios (see, Hosking and Wallis, 1997) between a certain point and regional average as follows:

$$
\begin{aligned}
& \mathbf{A}=\sum_{i=1}^{N}\left(\mathbf{u}_{i}-\overline{\mathbf{u}}\right)\left(\mathbf{u}_{i}-\overline{\mathbf{u}}\right)^{\mathrm{T}} \quad \text { and } \\
& D=\frac{1}{3} N\left(\mathbf{u}_{i}-\overline{\mathbf{u}}\right)^{\mathrm{T}} \mathbf{A}^{-1}\left(\mathbf{u}_{i}-\overline{\mathbf{u}}\right),
\end{aligned}
$$

where $N$ is the number of points within a region, and $\mathbf{u}_{i}$ and $\overline{\mathbf{u}}$ are $L$-moment ratios of a certain point and the regional average, respectively. The $L$-moment ratios were calculated with the frequency distribution of annual maxima of wave heights.

A region satisfying these three criteria was defined as a homogeneous region. The mean of annual maxima of wave heights $\left(H_{\mathrm{ann}}\right)$ was analyzed as an extreme value of non-TC waves.

\section{2) TC WAVES IN THE WNP}

TC waves were defined as waves within $500 \mathrm{~km}$ of the TC center. For this part of the analysis, a homogeneous region for the regional frequency analysis was defined with items (i) and (ii) from above since only TC waves are of interest. The climatological values in item (ii) were defined for the summer and autumn seasons (June-November) and normalized by the standard deviation of the WNP domain. The $R$ year return period wave height $H_{R}$ was analyzed as an extreme value for TC waves. The duration of sampling was considered to be $25 \mathrm{yr}$ multiplied by the number of grid points in the homogeneous region. The value for $H_{R}$ was estimated directly from the order statistics not using parametric representation and was calculated as

$$
H_{R}=w x_{k}-(1-w) x_{k+1},
$$

where $x_{k}$ is the $k$ th largest value and $w$ is the weight factor for interpolation. The value of $k$ is

$$
k=\operatorname{ceil}\left(\frac{N}{\lambda R}\right)
$$

where $N$ is the number of all data, $\lambda$ is the mean yearly occurrence of TC waves, and ceil() is the ceiling function. The value of $w$ is

$$
w=\frac{N}{\lambda R}-\operatorname{ceil}\left(\frac{N}{\lambda R}\right) .
$$

In this study, the atmospheric field of TCs is projected by a $60-\mathrm{km}-m e s h$ AGCM horizontally, which is a relatively higher resolution compared with currently available GCMs in phase 5 of CMIP (CMIP5; Taylor et al. 2012), and TC waves in the WNP are resolved by $0.5^{\circ}$ as described in section 2a. TCs (and TC waves) ideally require finer resolution to represent accurately the structure near the eye. A climate projection with AGCM is a better method than a regional model in terms of representation of the interaction between the TCs and the large-scale environment, and being free from arbitrary choices of domain size, boundary conditions, and so on (Manganello et al. 2012). Some studies (e.g., Murakami and Sugi 2010; Manganello et al. 2012) investigated the effects of the AGCM's spatial resolution $(10-180 \mathrm{~km})$ on TC climatology and indicated that a higher-resolution model showed better representation of intense TC. Murakami and Sugi (2010) concluded that $60-\mathrm{km}$ resolution is the critical resolution of MRIAGCM for projecting future change in the frequency of intense TCs. The representation of TCs in the AGCM of this study is shown in detail below (section 3 ).

Furthermore, a representation of accurate TC wave fields also requires finer resolution than $0.5^{\circ}$ (Tolman and Alves 2005; Ardhuin et al. 2010). We conducted test simulations with the finer resolution $\left(0.167^{\circ}\right)$ and found that the results of this study on TC wave climatology do not significantly depend on the wave model resolution compared with conditions of TC wind forcing.

\section{Validation of model for extreme wave climate}

Shimura et al. (2015) validated the use of the same GCM and wave model combination to project mean wave climates. Here, we validate the GCM and wave model combination for extreme wave climates. Simulated extreme wave climate data are estimated and compared with reanalysis datasets and in situ buoy data.

Since a certain reanalysis dataset has specific bias (Stopa and Cheung 2014), two different reanalysis datasets were used for this comparison. One is the ERAInterim dataset, developed by the European Centre for Medium-Range Weather Forecasts (Dee et al. 2011), which is widely applied to wave climate study (e.g., Hemer et al. 2013). The other is the Japanese 55-year Reanalysis Project (JRA-55), developed by the Japan Meteorological Agency (Kobayashi et al. 2015) and released in 2013 [Climate Forecast System Reanalysis (CFSR) data are also relevant, but the wave analysis data were not available at the time of this study as a result of server problems]. One of the major facets of JRA-55 is extreme weather, especially tropical cyclones in the western North Pacific. The JRA-55 assimilated 
(a) ERA interim

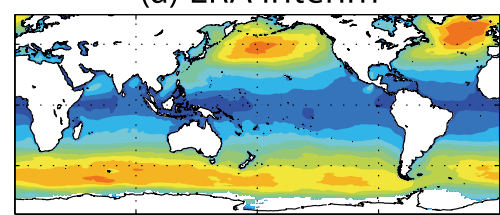

(d) HPA_YS

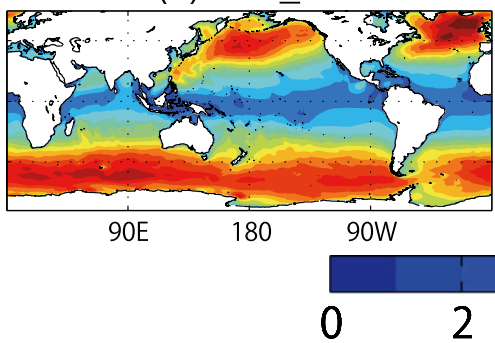

(g) ERAint - ST2

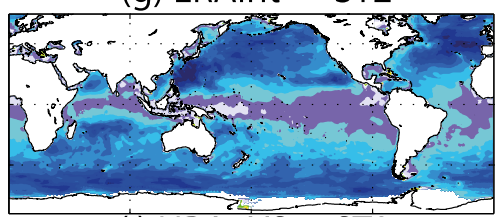

(i) HPA_YS - ST2

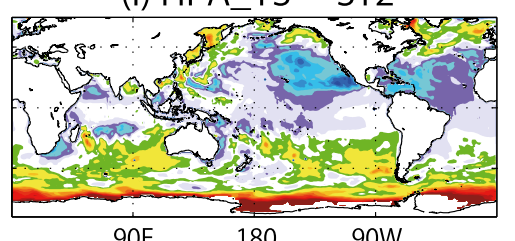

$90 \mathrm{E}$ (b) JRA55 ST2

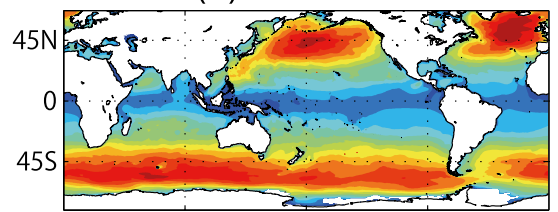

(e) HPA_AS

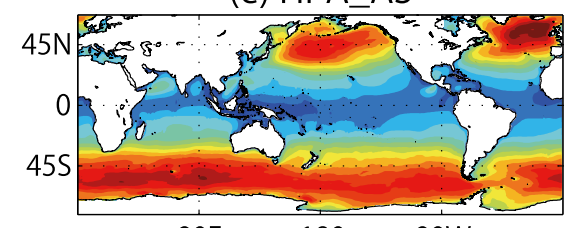

(c) JRA55 ST4

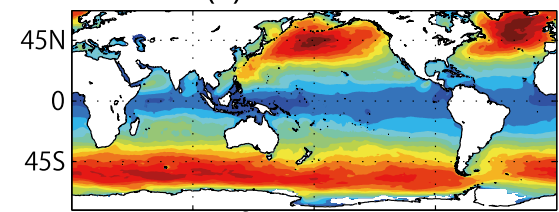

(f) HPA KF

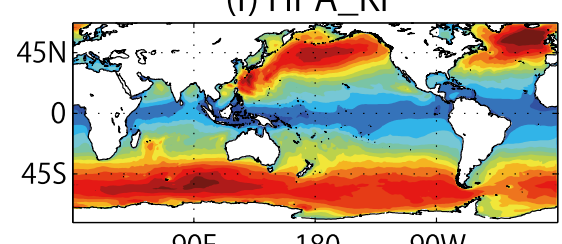

$90 \mathrm{E}$

$18090 \mathrm{~W}$

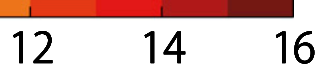

(h) JRA55 ST4 - ST2
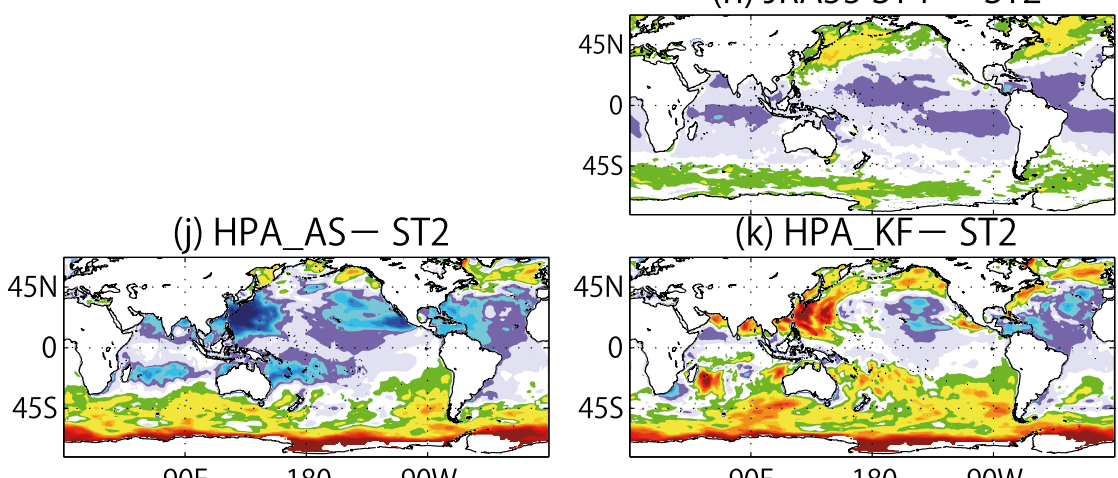

(k) HPA_KF-ST2

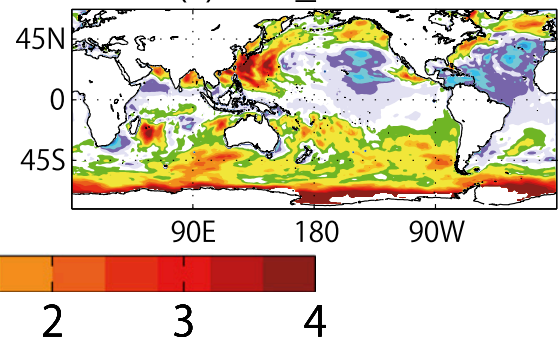

FIG. 2. Mean annual maximum wave height (m) for (a) ERA-Interim, (b) JRA-55 ST2, (c) JRA-55 ST4, (d) HPA_YS, (e) HPA_AS, and (f) HPA_KF; and differences (m) of $H_{\text {ann }}$ for (g) ERA-Interim - JRA-55 ST2, (h) JRA-55 ST4 - JRA-55 ST2, (i) HPA_YS - JRA55 ST2, (j) HPA_AS - JRA-55 ST2, and (k) HPA_KF - JRA-55 ST2.

artificial TC information using observational data (airborne data were used before satellite periods) to improve the representation of TC.

Murakami (2014) summarized tropical cyclone characteristics in state-of-the-art reanalysis datasets and concluded that the JRA-55 is the best of the reanalysis datasets. The ERA-Interim used a coupled atmospheric and wave model, but the JRA-55 dataset does not include wave data. Therefore, a long-term wave climate was calculated with the wave model WAVEWATCH III, version 4.18 (Tolman 2014), using sea surface wind and sea ice data from JRA-55. (Note that the wave climate projection of this study was calculated with WAVEWATCH III, version 3.14, using sea surface wind.) The source term of the wave models has improved in recent years, and new source term packages are available (e.g., Ardhuin et al. 2010). Therefore, the wave climate simulations based on JRA-55 were conducted by different source term packages of WAVEWATCH III. We performed analyses with the Tolman and Chalikov (1996) source term package (ST2) and the Ardhuin et al. (2010) source term package (ST4) to estimate how the extreme wave climate depends on source terms.

Figure 2 shows $H_{\text {ann }}$ during the period 1979-2003 for ERA-Interim (Fig. 2a), JRA-55 with the Tolman and Chalikov (1996) source term package (denoted by JRA55 ST2; Fig. 2b), JRA-55 with the Ardhuin et al. (2010) source term package (denoted by JRA-55 ST4; Fig. 2c), HPA_YS (Fig. 2d), HPA_AS (Fig. 2e), and HPA_KF (Fig. 2f). The differences between the results for Figs. 2a-f and JRA-55 ST2 are illustrated in Figs. 2g-k, respectively.

It is clear that $H_{\text {ann }}$ for ERA-Interim is smaller than for the others by $2-3 \mathrm{~m}$ over the middle-to-high latitudes and by $4 \mathrm{~m}$ over the typhoon region in the WNP. The ERA-Interim underestimated extreme wave heights; 
this is consistent with other studies (e.g., Stopa and Cheung 2014). The differences due to wave modelingthat is, between JRA-55 ST2 and ST4-are about $1 \mathrm{~m}$ in the WNP and the North Atlantic. The differences have specific spatial tendencies, namely, that extreme waves of ST4 are larger than ST2 extreme waves over the windwave-dominated regions and smaller over swell-dominated regions. This result is expected since ST4 has an improved swell dissipation term. The differences between the JRA55 with ST2 and the HPA series are significant over the high latitudes of the Antarctic Ocean and TC passing regions. The differences in the Antarctic Ocean are mainly due to the absence of sea ice simulations in the HPA series.

The spatial distributions of the differences of non-TC $H_{\text {ann }}$ between the HPA series and JRA-55 ST2 (not shown) can be characterized by larger waves (by about $1 \mathrm{~m}$ ) for the HPA series over the higher latitudes (south of $30^{\circ} \mathrm{S}$ in the Southern Hemisphere and north of $45^{\circ} \mathrm{N}$ in the Northern Hemisphere) and with smaller waves (by about $1.5 \mathrm{~m}$ ) over the Northern Hemisphere in the midlatitudes $\left(30^{\circ}-40^{\circ} \mathrm{N}\right)$. As shown above, the extreme wave climate projected with the HPA series is similar to that for JRA-55 when compared with ERA-Interim; however, there are systematic spatial differences and significant differences in the TC waves. We will compare the model results with buoy observations quantitatively and estimate how TC-generated waves contribute to the extreme wave climate in the following section.

\section{a. Comparison with buoy observations}

Long-term observations (longer than $19 \mathrm{yr}$ ) by moored buoys in the North Pacific (from the Japan Meteorological Agency and the U.S. National Oceanographic Data Center) were used for extreme wave climate validation. Quantile-quantile (QQ) plots of wave heights between observed buoy data and simulated data are shown. Five buoys along the Pacific Rim were selected: 46035 (19852011), 21004 (1982-2000), 51001 (1981-2009), 46006 (1977-2011), and 46003 (1976-99). Figure 3 shows the QQ plots for each buoy, and a map of the North Pacific illustrating each buoy location (a QQ plot of wind speed is shown in Fig. S1 of the supplementary material).

The QQ plots are shown by $50 \%, 90 \%, 99 \%, 99.9 \%$, $99.99 \%$, and $100 \%$ (period maximum) quantities. In the Fig. 3 legend, the value following a series name indicates $H_{\text {ann }}\left(H_{\text {ann }}\right.$ is not calculated for each buoy since they are not operated year-round); $H_{\text {ann }}$ roughly corresponds to the $99.9 \%$ quantiles. For the HPA and JRA-55 series, the quantiles greater than $90 \%$ are larger than those for ERA-Interim, except for HPA_AS at buoy 21004, which is a TC passing region in the WNP. Furthermore, the extreme waves of HPA_KF are much larger than buoy observations at buoy 21004. The model performance to simulate TC waves is discussed in detail in the next subsection. The extreme waves of the HPA series are similar across the HPA series and are roughly comparable with buoy observations except for buoy 21004. The differences due to wave modeling as shown by JRA-55 ST2 and ST4 are smaller than the differences among the HPA series and between the HPA, JRA-55, and ERAInterim.

\section{b. TC characteristics in the WNP}

The TC characteristics and the TC-generated waves in the WNP are discussed here. For this part of the analysis, we used observed TC data from the International Best Track Archive for Climate Stewardship (IBTrACS; http://www.ncdc.noaa.gov/ibtracs/) provided by the Japan Meteorological Agency. The IBTrACS data from 1979 to 2003 were selected following the analysis data period. Frequency distributions were calculated to compare between the HPA, JRA-55, and observation data; Figs. 4a,b show frequency distributions of minimum central pressure and maximum wind speed for the TC durations for the WNP.

When compared with observations, all the HPA experiments underestimate the frequency of intense TCs, especially HPA_AS, which did not reproduce intense TCs with minimum pressure less than $970 \mathrm{hPa}$ (Fig. 4a). The number of TCs with pressures less than $960 \mathrm{hPa}$ simulated by JRA-55, HPA_YS, HPA_AS, and HPA_KF are $10 \%, 36 \%, 0 \%$, and $64 \%$ of observations, respectively. The wind speeds from HPA_YS and HPA_KF show better agreement with observations (Fig. 4b) than did their comparisons of minimum pressure. This is because wind speeds corresponding to minimum pressures are overestimated in the HPA experiments. Wind speed is a major factor behind extreme waves. TCs with winds stronger than $40 \mathrm{~m} \mathrm{~s}^{-1}$ for JRA-55, HPA_YS, HPA_AS, and HPA_KF are 26\%, $54 \%, 0 \%$, and $91 \%$ of observations, respectively. It is clear that the ability to simulate TC-related extreme winds strongly depends on the cumulus physics.

Figure $4 \mathrm{c}$ is a frequency distribution of the maximum wave height for TCs in the WNP. This distribution (Fig. 4c) corresponds well with the maximum wind speed distribution (Fig. 4b) because of the strong relationship between maximum wind speed and wave height during TC duration as shown in Fig. 4d. There are small differences between JRA-55 ST2 and ST4 (Fig. 4c). Although differences in wave physics modeling under high winds can significantly affect the representation of TC wave fields (Tolman and Alves 2005; Chao and Tolman 2010; Ardhuin et al. 2011), TC wave climatology does not depend on wave physics modeling compared with the conditions of TC wind forcing. 

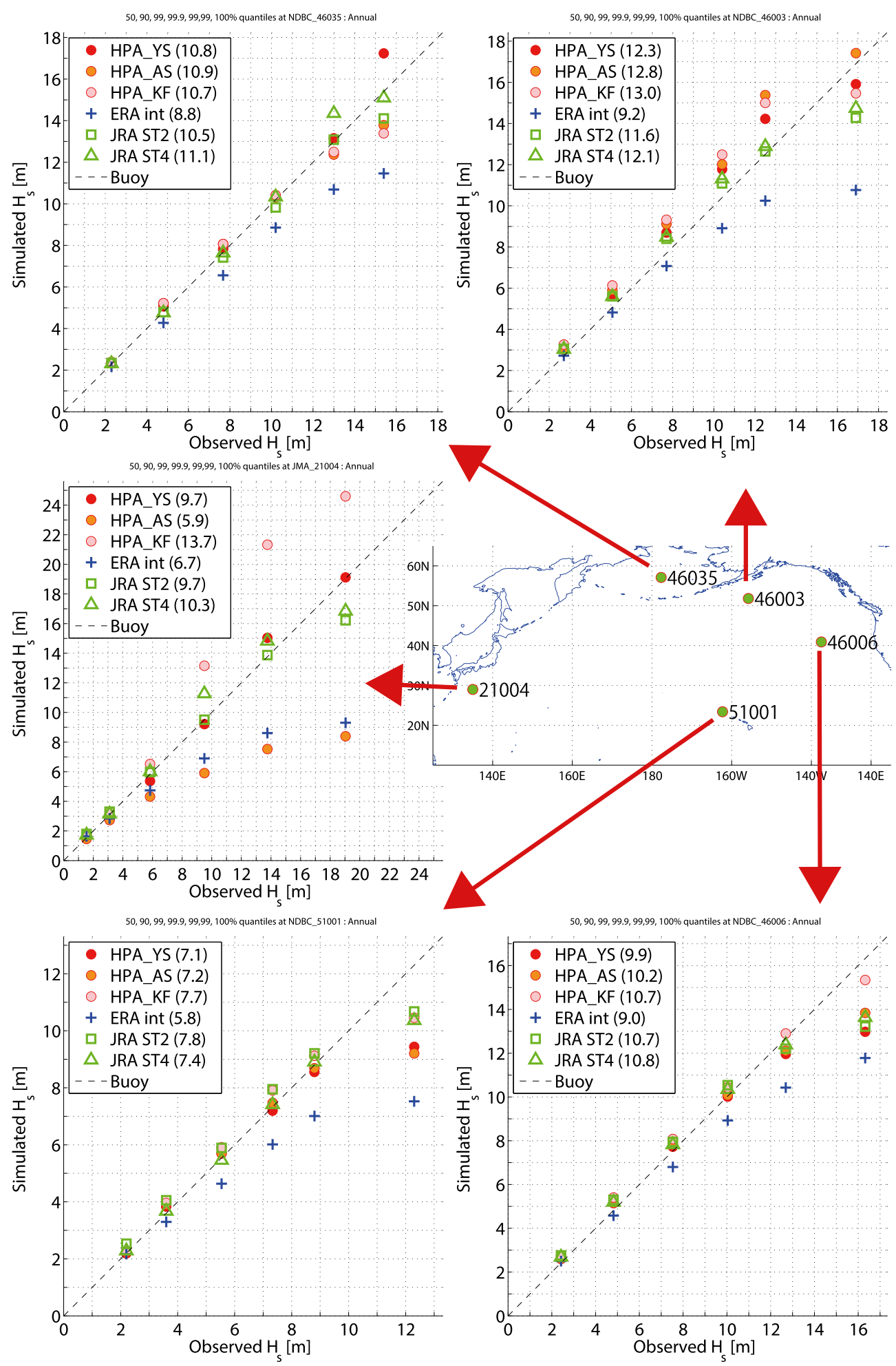

FIG. 3. Comparison of analysis results with buoy data by QQ plot $(50 \%, 90 \%, 99 \%, 99.9 \%, 99.99 \%$, and $100 \%$ quantiles). The values in the legend indicate $H_{\text {ann }}(\mathrm{m})$. 

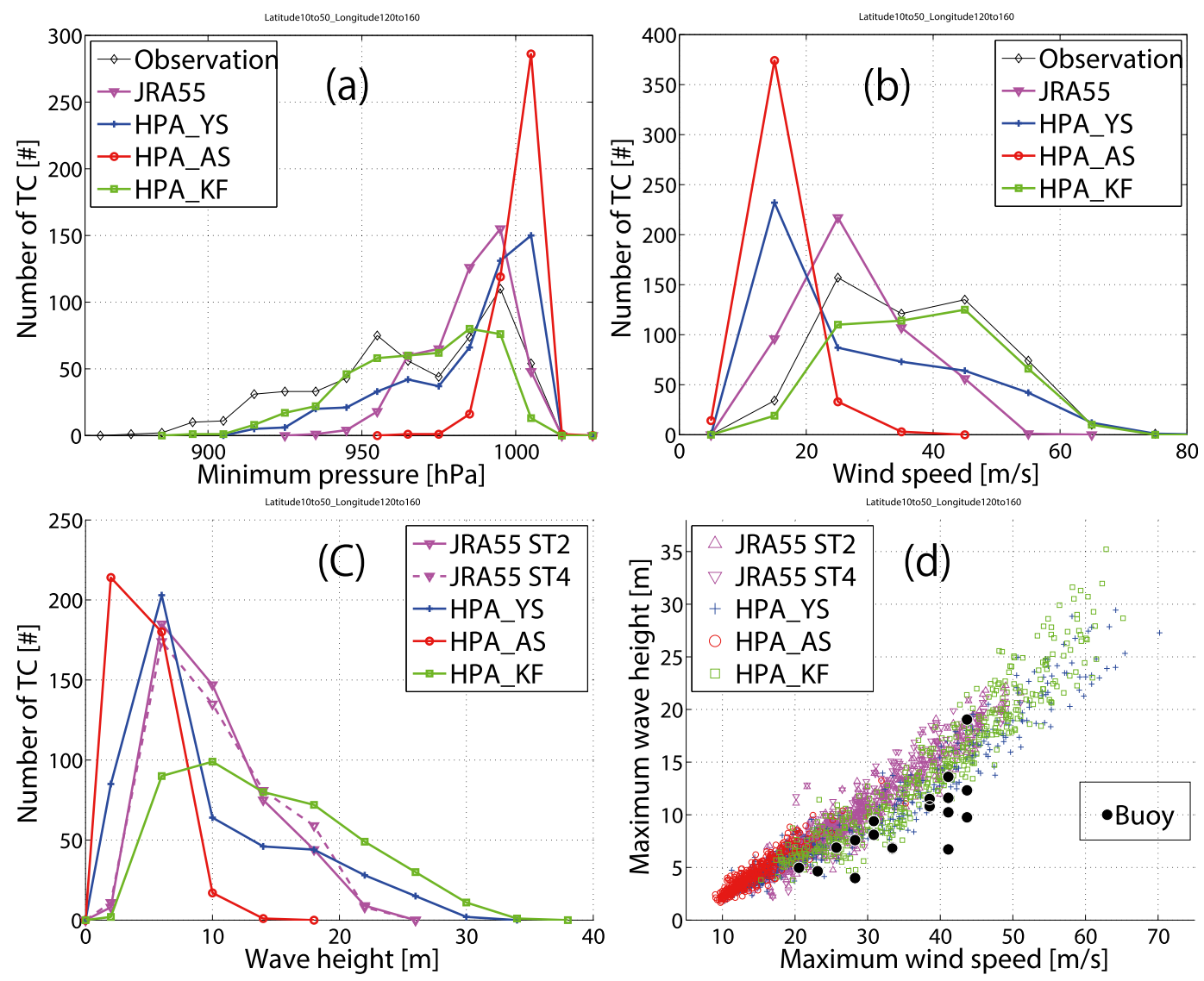

FIG. 4. Frequency distributions of TC characteristics in the WNP from 1979 to 2003: (a) minimum central pressure, (b) maximum wind speed, (c) maximum wave height, and (d) relationship between maximum wind speed and wave height [black dots in (d) indicate observed relationship by moored buoys (21004 and 22001) when the waves were observed within $100 \mathrm{~km}$ on the right side of the TC traveling direction].

Regarding the simulation of intense TCs, HPA_KF performs best when compared with observations (Figs. 4a,b). However, Fig. 3 shows that HPA_KF overestimates extreme waves over the WNP (buoy 21004), and that HPA_YS and JRA-55 show better agreement with buoy observation. This seeming contradiction is because buoys, or in situ observations, could not observe the waves under extremely intense TC conditions.

To illustrate this, the model results and data for the moored buoys in the WNP [buoys 21004 and 22001 $\left.\left(28.1^{\circ} \mathrm{N}, 126.2^{\circ} \mathrm{E}\right)\right]$ are plotted in Fig. $4 \mathrm{~d}$. To approximate the TC maximum wave heights, we conditionally collected buoy observation data when waves were observed within $100 \mathrm{~km}$ and on the right side of the TC traveling direction. The maximum wind speeds in the plot were obtained from the TC best track data and corresponded with the time when the buoys observed the approximate maximum wave heights. In Fig. 4 d, the HPA series show reasonable results. Although HPAs tend to overestimate the maximum wave heights' corresponding wind speeds when compared with the observations, HPA overestimation of wave height is reasonable because observed maximum wave heights culled from buoy data are smaller than actual maximum wave heights. There are no data of TC waves in the buoy observations when the maximum wind speed is more than $45 \mathrm{~m} \mathrm{~s}^{-1}$ (Fig. 4d) because the buoys have not been close to the eyes of such intense TCs over the period of observation. For this reason, HPA_KF overestimates the extreme waves and the less accurate models; and HPA_YS and JRA-55 show good agreement with buoy observations (Fig. 3; buoy 21004).

HPA_YS and HPA_KF have more reasonable simulations of TCs than JRA-55, which has the best performance for forecasting TCs in state-of-the-art reanalysis (Murakami 2014). An additional revelation is that HPA_AS does not adequately simulate TC extreme waves. Thus, HPA_AS is excluded for the analysis of TC extreme waves in the following sections. 

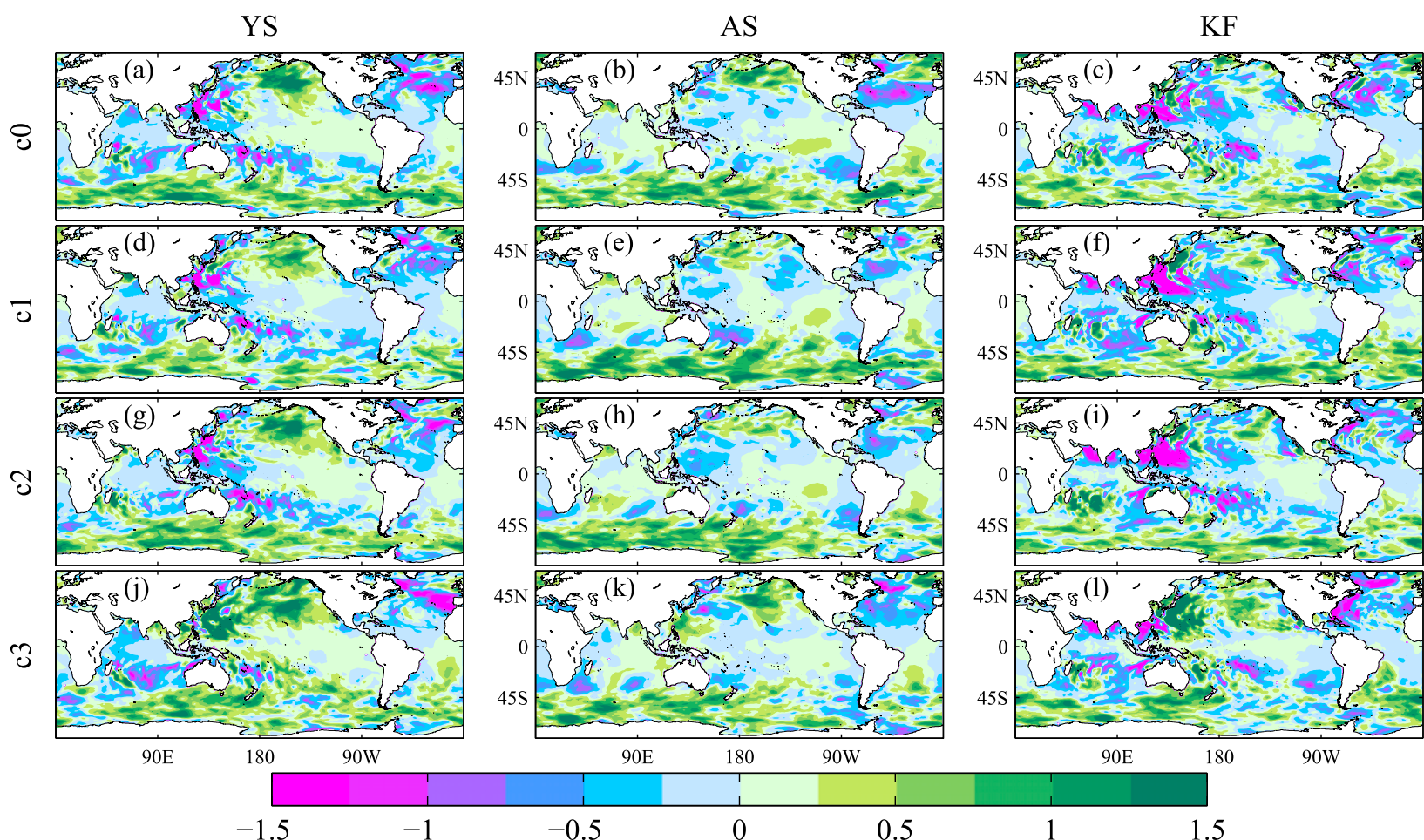

FIG. 5. Future changes in $H_{\mathrm{ann}}$ for TC waves (m), where color shading denotes future climate minus present climate, columns are grouped by mean PP ensemble for (left)-(right) YS, AS, and KF; and rows are grouped by SST ensemble for (top)-(bottom) c0-c3.

\section{Future changes in extreme wave climate}

Future changes in extreme wave climate are discussed in this section. Figure 5 shows the future changes in $H_{\text {ann }}$ (including non-TC and TC waves) for 12 experiments. The changes due to TC and non-TC effects can be seen clearly in the series of YS and KF experiments by comparing the results of the AS experiment to the other. Note that changes due to TC effects are not as pronounced in the series of AS experiments because the AS series simulations do not accurately simulate TCs as described in the previous section. It is clear that future changes in extreme wave height strongly depend on TC model performance as shown in Fig. 5. Future changes in TC and non-TC waves can be different from each other in character. Therefore, they are discussed separately in the following sections.

\section{a. Non-TC extreme waves}

Figure 6 shows future changes in $H_{\text {ann }}$ for non-TC waves for each experiment. Figure 6 also shows the ensemble mean value of future changes in $H_{\text {ann }}$ among each SST and PP ensemble experiment (Figs. 6d,h,l,p, and $6 \mathrm{q}-\mathrm{s}$ ), and all the experiments (Fig. 6t). The spatial distribution of the future changes of each experiment is qualitatively similar to the overall mean (Fig. 6t). The spatial distribution of future $H_{\text {ann }}$ change can be characterized by increases in wave heights over the middleto-high latitudes in the Southern and central North Pacific Oceans by up to $1 \mathrm{~m}$, and decreases over the midlatitudes and the North Atlantic by up to $-1 \mathrm{~m}$. This spatial distribution is similar to that of future changes in mean wave heights (Shimura et al. 2015) and $H_{\text {ann }}$ in wintertime.

Furthermore, this spatial distribution is similar to the future changes in mean wave heights shown in IPCC (2013), which is a summary of previous studies. Therefore, wintertime extratropical storms determine future changes in mean and non-TC extreme wave characteristics. Additionally, Fig. $6 \mathrm{t}$ is quite similar to changes in $H_{\text {ann }}$ published by Wang et al. (2014, their Fig. 2b), although $H_{\text {ann }}$ was derived from all the wave data, whereas Fig. 6 shows only non-TC wave data. An explanation for this similarity is that changes in $H_{\text {ann }}$ by Wang et al. (2014) are dominated by non-TC effects since the model and scheme used have a lower TC performance for extreme events. Therefore, the future changes in non-TC extreme waves mentioned above are consistent with another independent study.

The SST and PP ensemble results can be used to analyze the source of uncertainty with the projection. The variance of the future changes in non-TC $H_{\text {ann }}$ among 

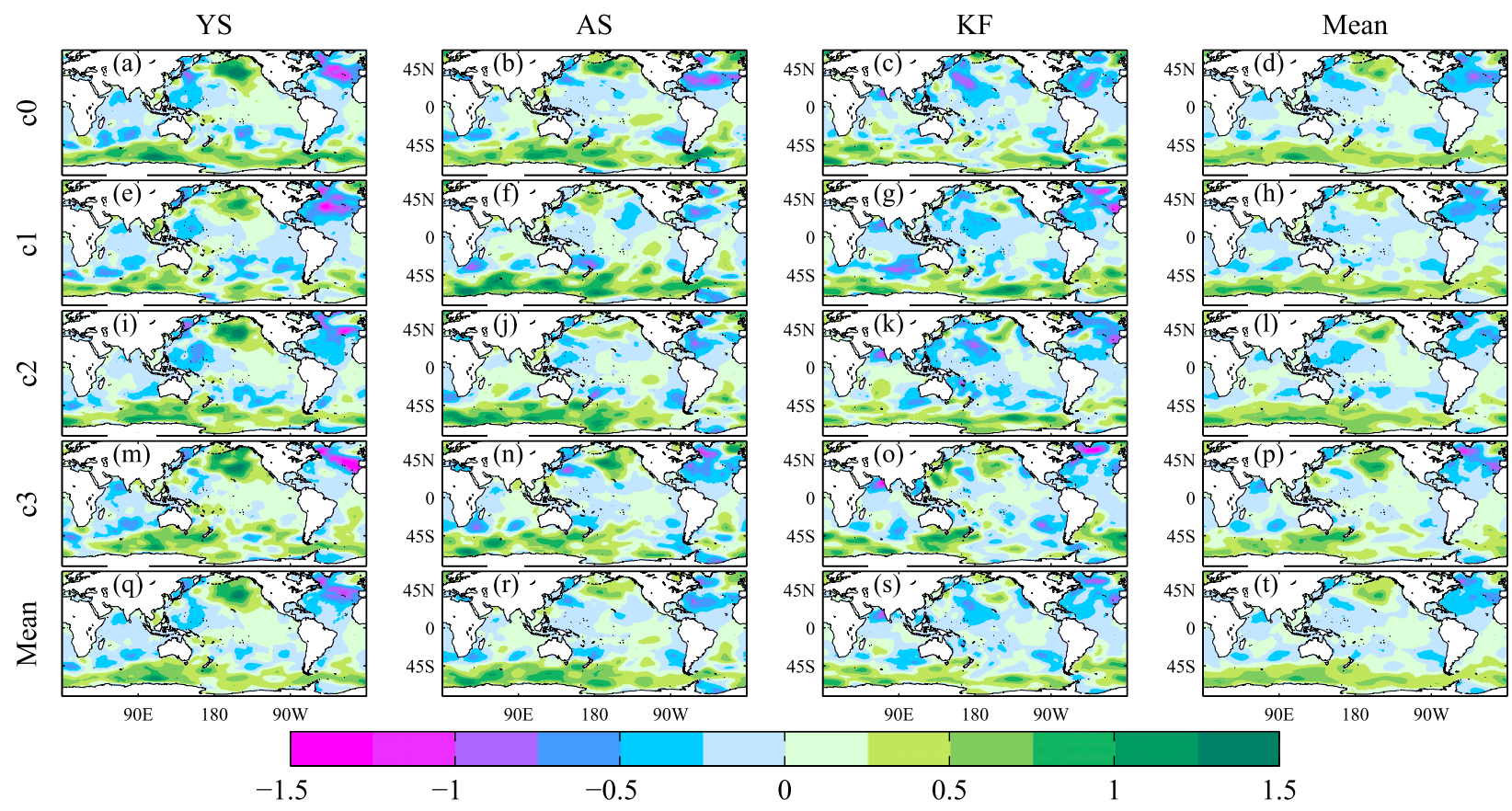

FIG. 6. As in Fig. 5, but for non-TC waves (m).

ensemble experiments was estimated quantitatively. Figure 7a shows the standard deviation of future changes in $H_{\text {ann }}$ among ensemble experiments at each grid point. The standard deviation is large (up to $0.7 \mathrm{~m}$ ) in the middle-to-high latitudes. To estimate how differences in
SST condition and physics contribute to the standard deviation, an analysis of variance (ANOVA; von Storch and Zwiers 1999) was performed. A two-way ANOVA without interaction (von Storch and Zwiers 1999) expresses the total sum of squares with three components, (a) STD [m]

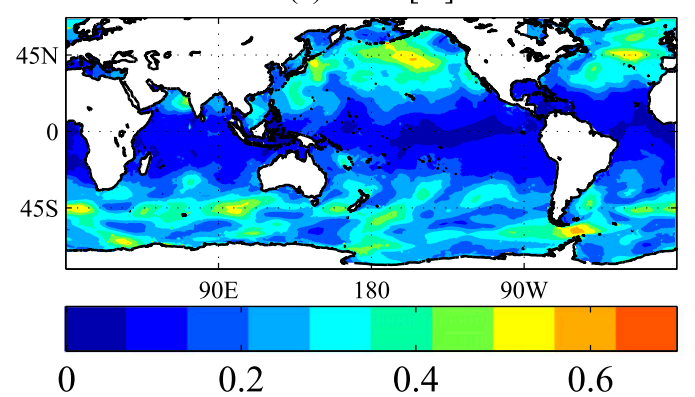

(c) Pphy [\%]

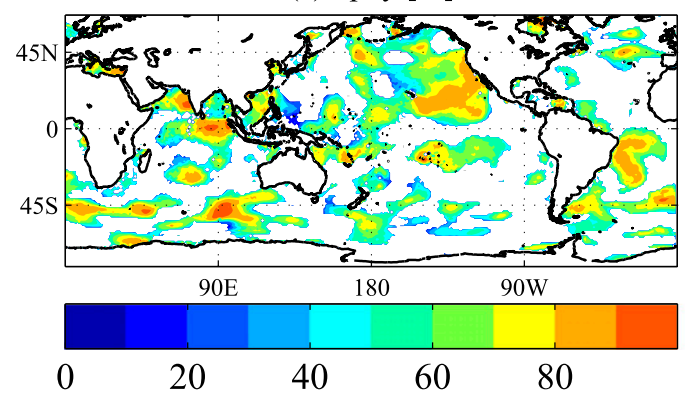

(b) Psst [\%]

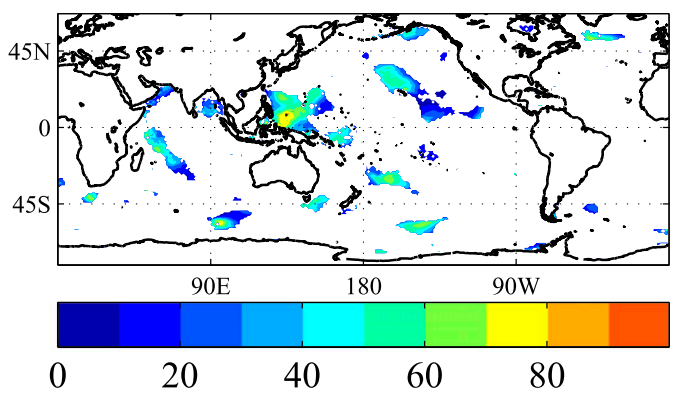

(d) Psst (mean) [\%]

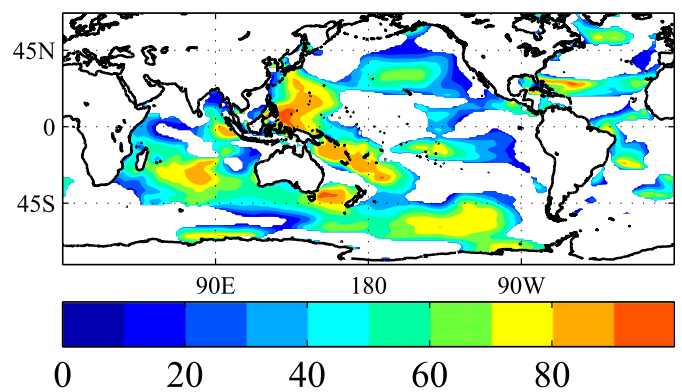

FIG. 7. Analysis of variance on future changes in non-TC $H_{\mathrm{ann}}$ : (a) standard deviation, (b) $P_{\mathrm{SST}}$, (c) $P_{\mathrm{phy}}$, and (d) $P_{\mathrm{SST}}$ of future changes in mean wave height. The values at the $5 \%$ statistically significant level are color shaded in (b)-(d). 

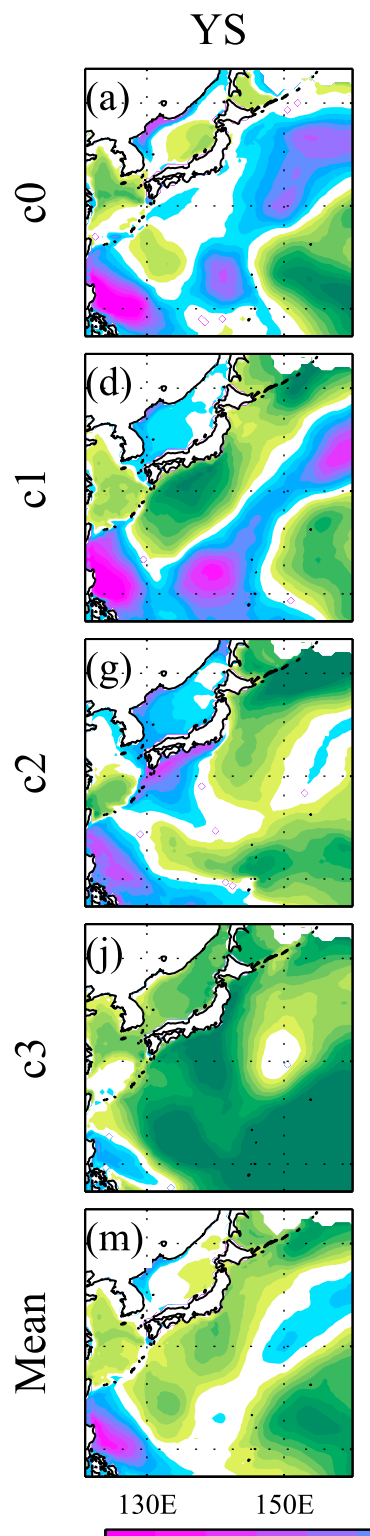
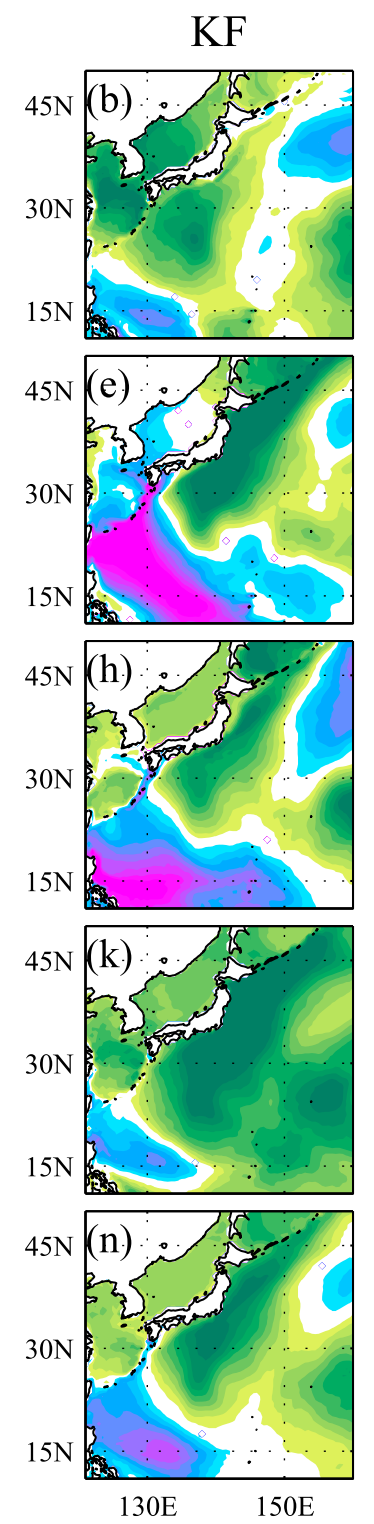
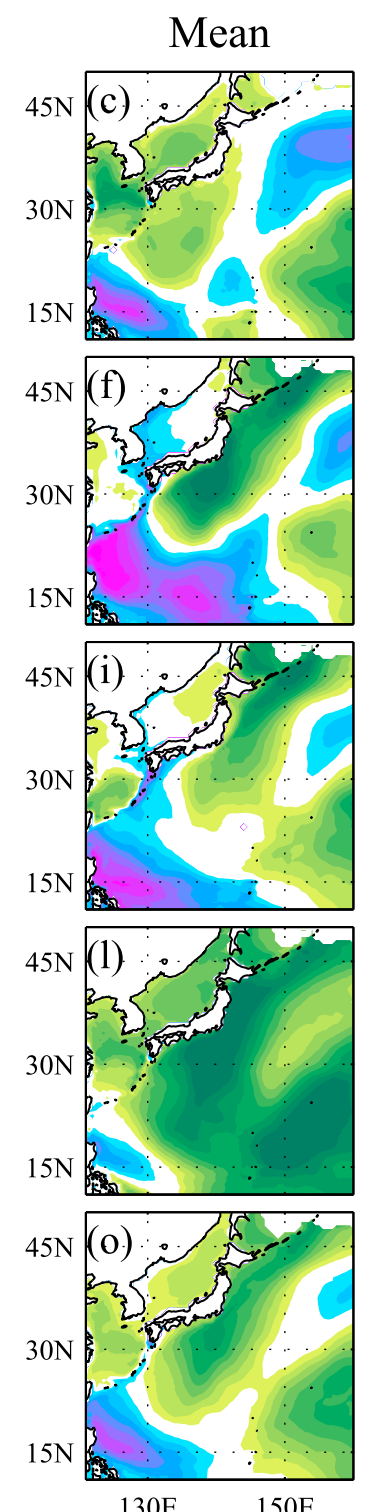

$130 \mathrm{E}-150 \mathrm{E}$

$$
-5
$$

0

FIG. 8. The $\Delta H_{10}$ for TC waves (m), where color shading denotes future climate minus present climate, columns are grouped by PP ensemble for (left)-(right) YS, AS, and KF]; rows are grouped by SST ensemble for (top)-(bottom) $\mathrm{c} 0-\mathrm{c} 3$, and colored regions indicate $\lambda \geq 0.1$ TC wave occurrence per year.

which are the sum of squares due to SST difference, physics difference, and the residual. Figures $7 \mathrm{~b}$ and $7 \mathrm{c}$ show the proportion of the sum of squares due to SST difference $\left(P_{\mathrm{SST}}\right)$ and physics difference $\left(P_{\text {phy }}\right)$, respectively.

Although the $P_{\mathrm{SST}}$ over the low latitudes of the WNP is about $70 \%$, the $P_{\text {SST }}$ over most of the ocean $(90 \%$ of the entire ocean) is not statistically significant at the $5 \%$ significance level. This result is opposite of the $P_{\mathrm{SST}}$ of future changes in mean wave heights (Fig. 7d), where values are significant over $50 \%$ of the entire ocean, and the values are greater than $50 \%$ over $27 \%$ of the entire ocean. Furthermore, the variance of future changes in mean wave heights depends on the SST difference over the region, where the standard deviation of the future changes in mean wave heights is relatively larger (not shown). On the other hand, the $P_{\text {phy }}$ of future changes in $H_{\text {ann }}$ is significant over $47 \%$ of the entire ocean and greater than $50 \%$ over $36 \%$ of the entire ocean (Fig. $7 \mathrm{c}$ ). 
(a) Present value $[\mathrm{m}]$

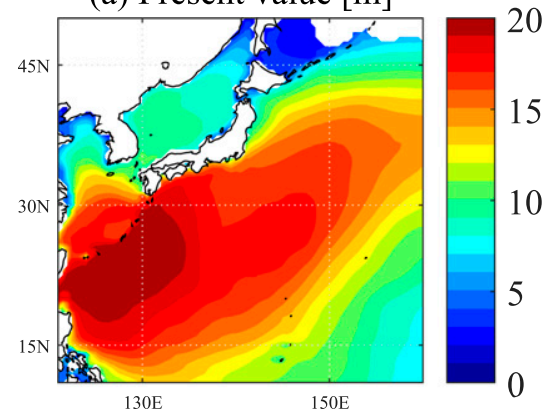

(c) Future change ratio $[\%]$
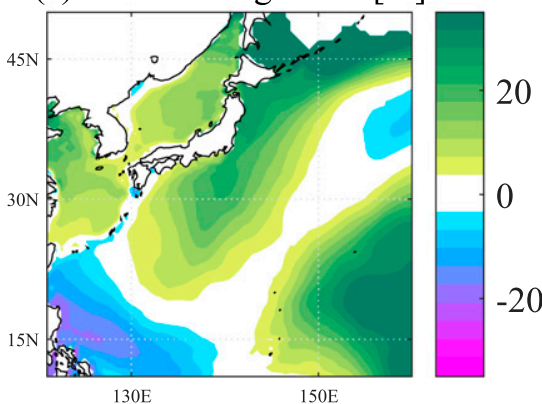

(b) Mean future change $[\mathrm{m}]$

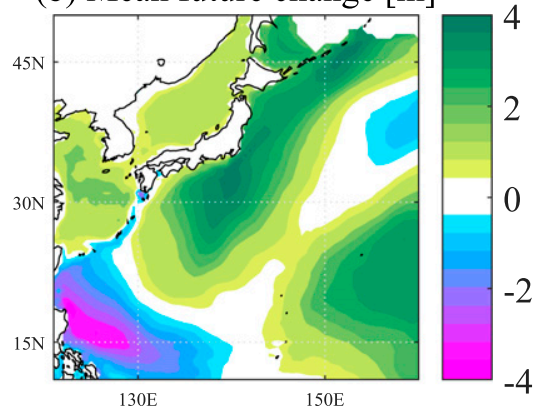

(d) STD [m]

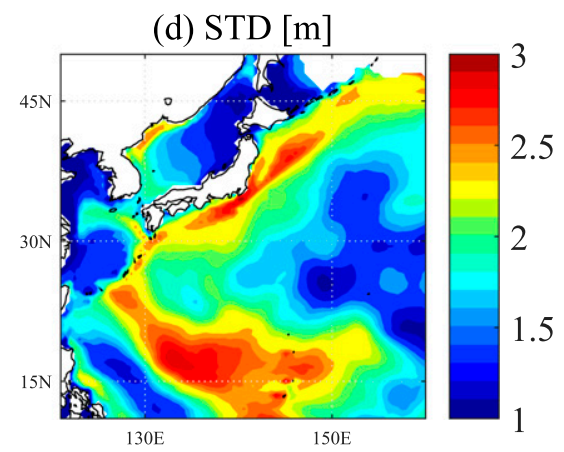

FIG. 9. Ensemble results of $H_{10}$ of TC waves and $\Delta H_{10}$ : (a) overall mean $H_{10}$ across present climate experiments (m), (b) $\Delta H_{10}$ (as in Fig. 8o; m), (c) future change ratio (\%), and (d) standard deviation of $\Delta H_{10}$ of eight experiments (m).

And, although not included here, the $P_{\text {phy }}$ of future changes in mean wave heights (not shown) is significant over $63 \%$ of the entire ocean.

Future changes in non-TC waves can be summarized as follows. The spatial distribution of future changes in non-TC extreme waves is similar to that of future changes in mean waves. However, the characteristics of variance of future changes in extreme and mean waves are quite different. Although the variance of future changes in mean waves significantly depends on the SST difference, the variance of future changes in extreme waves mainly depends on the cumulus convection scheme.

\section{b. TC extreme waves in the WNP}

To focus on the impact of TCs on extreme waves, the WNP was chosen since it is the basin with the most active TCs. To represent extreme waves, $H_{R}$ is analyzed. Figure 8 shows future changes in 10 -yr return period wave heights of TC waves $\left(\Delta H_{10}\right)$. The $H_{10}$ values change within a range of $5 \mathrm{~m}$ depending on the region. Although $\Delta H_{10}$ varies widely among ensemble experiments, each individual spatial distribution of $\Delta H_{10}$ is similar to the overall mean values shown in Figs. 80 and $9 \mathrm{~b}$, qualitatively. This spatial distribution of $\Delta H_{10}$ can be characterized by minus and plus alternating patterns, such as decrease, increase, decrease, and increase, clockwise from the southwestern part of the WNP to the southeastern part. The variation of $\Delta H_{10}$ is quite large, which is comparable in magnitude to the future change value itself. The overall mean of $\Delta H_{10}$ for all the experiments is $\pm 4 \mathrm{~m}$ (Fig. 9b), which is about $\pm 30 \%$ (Fig. 9c) of the present climate value (Fig. 9a), and the standard deviation is up to $3 \mathrm{~m}$ (Fig. 9d). Note that the variation is especially large along the southern coast of Japan.

Generally, future change in $H_{R}$ can be classified into TC wave intensity change and TC wave frequency change. The future change of $H_{R}\left(\Delta H_{R}\right)$ is represented with $H_{R}$ for the present and future climate $\left(H_{R}^{p}\right.$ and $H_{R}^{f}$, respectively) as

$$
\Delta H_{R}=H_{R}^{f}-H_{R}^{p} .
$$

The variable $H_{R}$ is represented by an inverse nonexceedance probability function $F$ and mean yearly occurrence of TC waves $\lambda$,

$$
\begin{aligned}
H_{R} & =F^{f}\left(\frac{1}{R \lambda^{f}}\right)-F^{p}\left(\frac{1}{R \lambda^{p}}\right) \\
& =F^{f}\left[\frac{1}{R \lambda^{p}}-\frac{\Delta \lambda}{R \lambda^{p}(1+\Delta \lambda)}\right]-F^{p}\left(\frac{1}{R \lambda^{p}}\right),
\end{aligned}
$$

where $\lambda^{f}=\lambda^{p}(1+\Delta \lambda)$ and $F$ is estimated directly not using parametric ways, such as Eq. (2). Rewritten by the Taylor series expansion, 


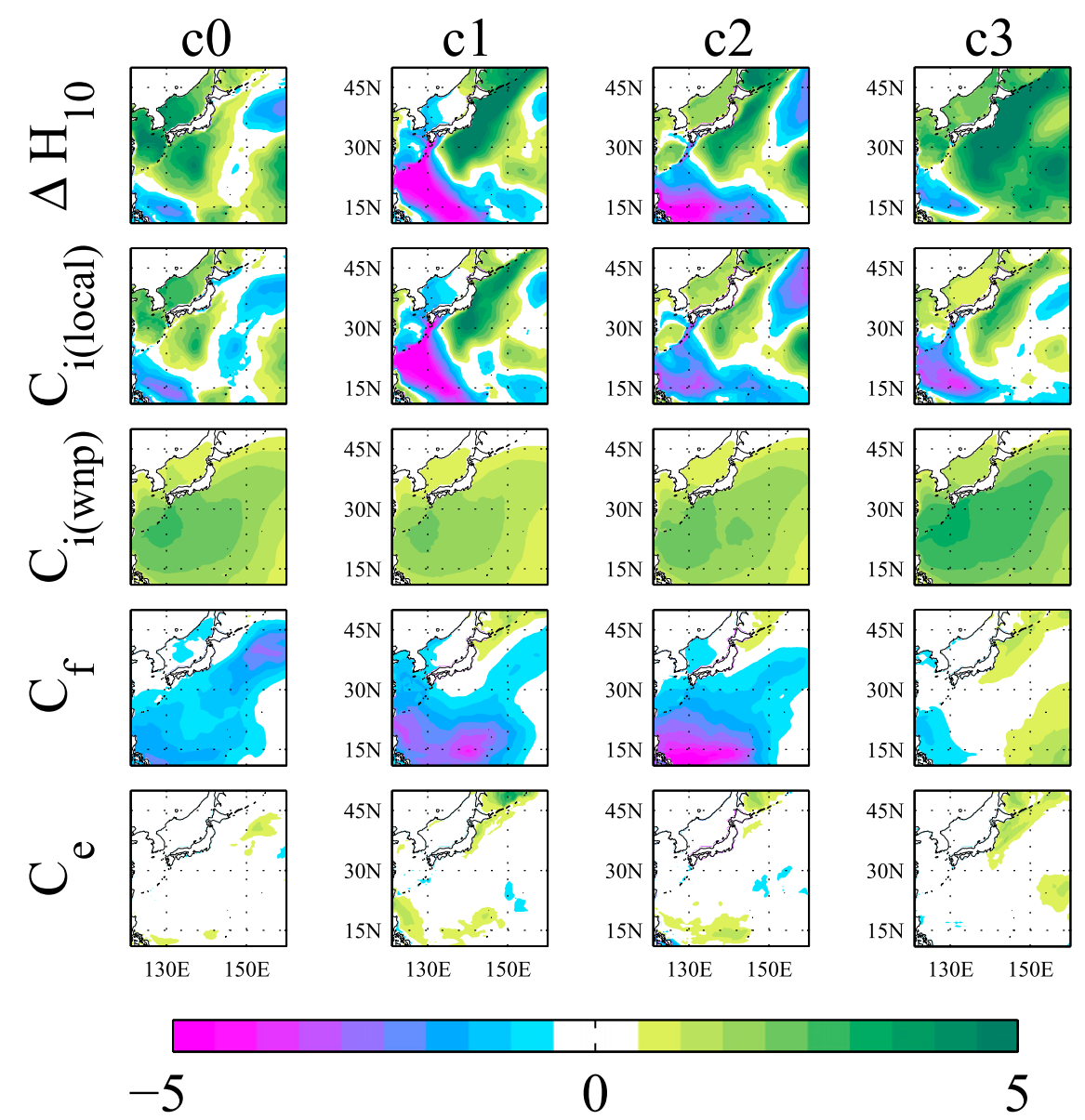

FIG. 10. Component analysis of $\Delta H_{10}$ in HFA_KF (m). The values of (top)-(bottom) $\Delta H_{10}$, $C_{i(\text { local })}, C_{i(\mathrm{nwp})}, C_{f}$, and $C_{e}$ are grouped by row, and the SST conditions are grouped by column.

$$
\begin{aligned}
= & {\left[F^{f}\left(\frac{1}{R \lambda^{p}}\right)-F^{p}\left(\frac{1}{R \lambda^{p}}\right)\right] } \\
& -\dot{F}^{f}\left(\frac{1}{R \lambda^{p}}\right) \frac{1}{R \lambda^{p}} \frac{\Delta \lambda}{(1+\Delta \lambda)}+E_{1},
\end{aligned}
$$

where $E_{1}$ includes higher-order terms of the Taylor series expansion. Term $\dot{F}^{f}$ is replaced by $\dot{F}^{p}$ and the residual is represented by $E_{2}$ :

$$
\begin{aligned}
= & {\left[F^{f}\left(\frac{1}{R \lambda^{p}}\right)-F^{p}\left(\frac{1}{R \lambda^{p}}\right)\right] } \\
& +\left[-\dot{F}^{p}\left(\frac{1}{R \lambda^{p}}\right) \frac{1}{R \lambda^{p}} \frac{\Delta \lambda}{(1+\Delta \lambda)}\right]+\left(E_{1}+E_{2}\right) .
\end{aligned}
$$

The first term is represented by the difference in $F$ with the probability of present climate $\left(R \lambda^{p}\right)^{-1}$, and this term can be considered a factor of TC wave intensity change $C_{i}$. The second term is represented by $F$ of present climate and frequency change $\Delta \lambda$, and this term can be considered a factor of TC wave frequency change $C_{f}$. The third term is a residual and nonlinear interaction factor.
Furthermore, the term $C_{i}$ can be regarded as representing the change between the entire WNP TC wave intensity and the local one. For $F(1 / R \lambda)=$ $\alpha(1 / R \lambda) F_{\text {wnp }}(1 / R \lambda), F_{\text {wnp }}$ is $F$ derived from all the TC wave data in the WNP and $\alpha$ is a local factor. Term $F_{\mathrm{wnp}}$ is identical over the WNP and $\alpha$ depends on the location (grid point). Here,

$$
\begin{aligned}
C_{i} & =\left(\alpha^{p}+\Delta \alpha\right) F_{\mathrm{wnp}}^{f}-\alpha^{p} F_{\mathrm{wnp}}^{p} \\
& =\alpha^{p} \Delta F_{\mathrm{wnp}}+\Delta \alpha F_{\mathrm{wnp}}^{p}+\Delta \alpha \Delta F_{\mathrm{wnp}},
\end{aligned}
$$

where $\Delta F_{\text {wnp }}=F_{\text {wnp }}^{f}-F_{\text {wnp }}^{p}$ and $\Delta \alpha=\alpha^{f}-\alpha^{p}$. The first term includes the difference of $F_{\text {wnp }}$ with the present climate local factor, and thus this term can be considered a factor of the change of basinwide TC wave intensity $C_{i(\mathrm{wnp})}$. The second term is represented by the difference of $\alpha$ and $F_{\text {wnp }}$ for the present climate, and thus this term can be considered a factor of local TC wave intensity $C_{i \text { (local) }}$. The third term is an interaction factor $E_{3}$. Finally, $\Delta H_{R}$ is represented as 


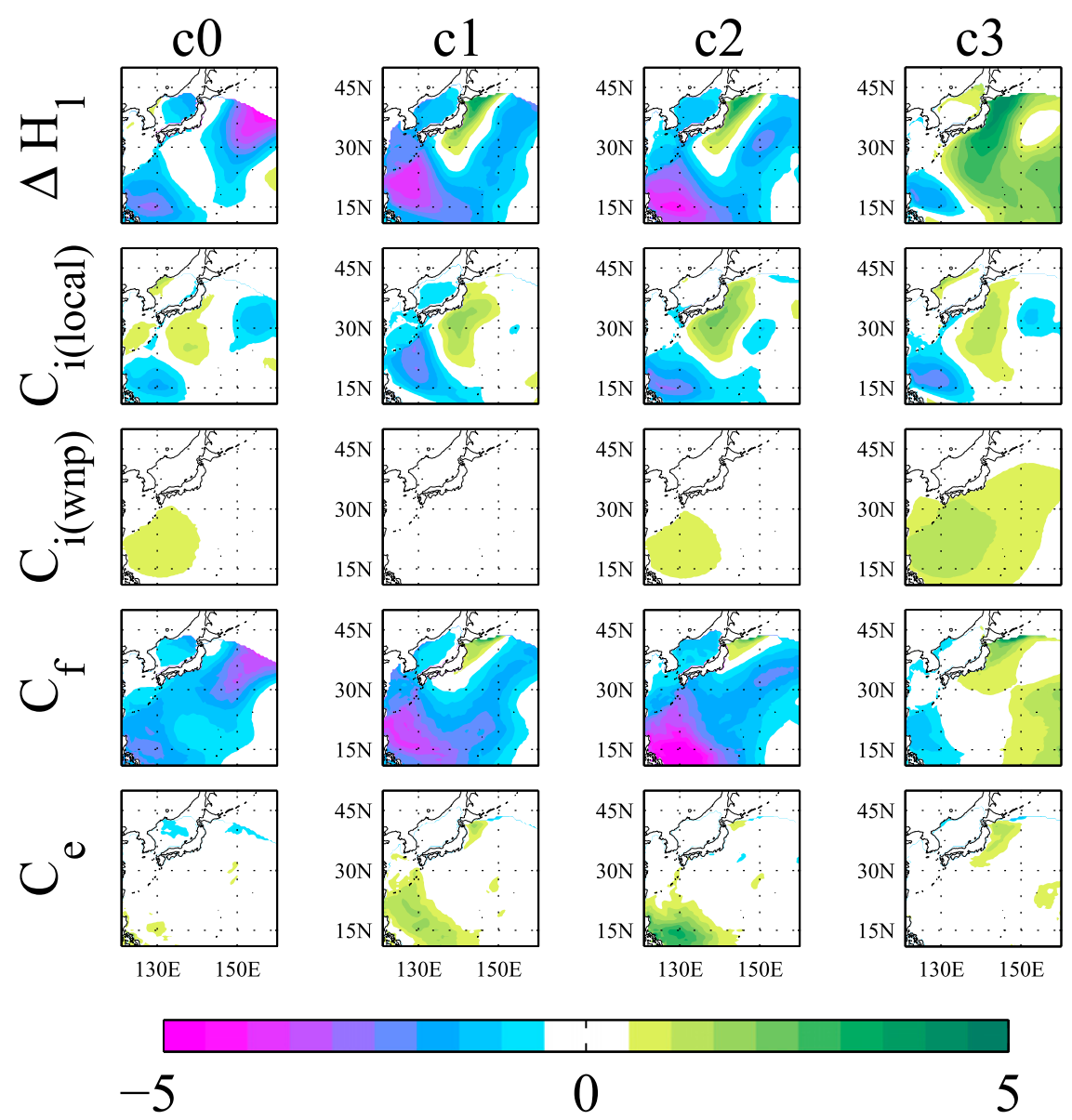

FIG. 11. As in Fig. 10, but for $\Delta H_{1}$ in HFA_KF (m). Colored regions indicate $\lambda \geq 1$ TC wave occurrence per year.

$$
\Delta H_{R}=C_{i(\mathrm{wnp})}+C_{i(\text { local })}+C_{f}+C_{e},
$$

where $C_{e}=E_{1}+E_{2}+E_{3}$. Using the abovementioned component analysis, Eq. (11) was applied to $\Delta H_{10}$.

Figure 10 shows $\Delta H_{10}$ for the HFA_KF series and the $C_{i(\text { local })}, C_{i(\mathrm{wnp})}, C_{f}$, and $C_{e}$. Term $C_{e}$ is small relative to the other factors. It is clear that $\Delta H_{10}$ (first row in Fig. 10) is dominated by $C_{i \text { (local) }}$ (second row in Fig. 10). Term $C_{i \text { (wnp) }}$ has a positive contribution on $\Delta H_{10}$ over the entire the domain, and $C_{f}$ contributes a secondary effect when compared with $C_{i(\text { local) }}$. Term $C_{f}$ for $\mathrm{c} 0-\mathrm{c} 2$ yields a negative contribution on $\Delta H_{10}$ over almost the entire domain. But $C_{f}$ for $\mathrm{c} 3$ is not a broadly negative contribution.

In Fig. 11, $C_{f}$ is the primary effect on $\Delta H_{1}$. Term $\Delta H_{1}$ for $\mathrm{c} 0-\mathrm{c} 2$ is negative over a vast area of the WNP, mainly because of $C_{f}$. However, $\Delta H_{1}$ for $\mathrm{c} 3$ is positive because $C_{f}$ is not negative. The difference in TC wave frequency between $\mathrm{c} 0-\mathrm{c} 2$ and $\mathrm{c} 3$ is discussed in detail by Shimura et al. (2015). And, the component analysis results for the KF scheme hold true for the YS scheme.
The spatial distribution of $\Delta H_{10}$ can be explained by future changes in TC tracks. Only intense TCs with minimum pressures less than $950 \mathrm{hPa}$ are shown hereafter. The threshold value of $950 \mathrm{hPa}$ is an arbitrary value, but the results are not significantly changed with values of 940 or $960 \mathrm{hPa}$.

Figure 12 shows the frequency ratio of TC passing with contour lines and the future change with color variations. Prevailing tracks in the present climate can be represented with three tracks (black arrows in Fig. 12). One track is directed westward from the generation area in the low latitudes, and the other tracks are directed north and northeast toward the midlatitudes. These prevailing TC tracks can be also seen in observation data (Wu et al. 2005).

Note that the relative frequency of TCs decreases over the low latitudes in the future climate. For the other two northward prevailing tracks, the relative frequency of TCs also decreases in the future climate. The red arrows in Fig. 12 illustrate an eastward shift of TC tracks and an increase in TC frequency in those areas. Also, the 


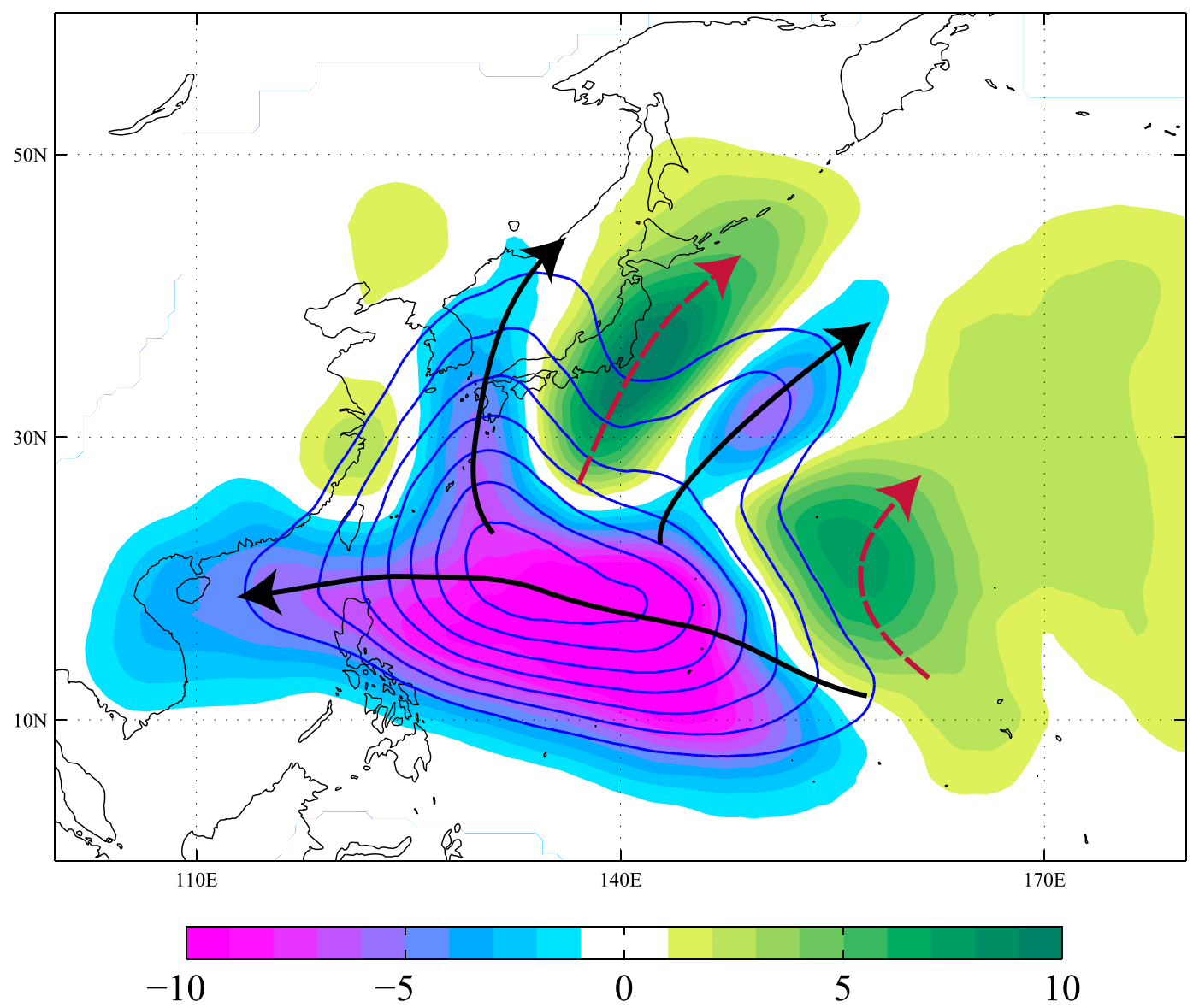

FIG. 12. Frequency ratio of number of TC passing and its future change. Contour lines indicate the frequency ratio in the present climate (from $10 \%$ to $40 \%$ in $5 \%$ increments). Color gradations indicate future changes (percent point). Arrows are prevailing tracks of TCs (black arrows are those in the present climate and red arrows are increased tracks in the future climate).

spatial distribution of $\Delta H_{10}$ (Fig. 9a) corresponds to a TC track shift (Fig. 12). In the discussion on $\Delta H_{10}$, it was noted that $\Delta H_{10}$ is dominated by factor $C_{i(\text { local })}$. Term $C_{i(\text { local })}$ can be considered a result of the eastward shift of TC tracks.

To summarize the above discussion, $C_{i(\text { local })}$ is positive in regions where TCs are projected to pass closer, resulting in an increase in TC waves in the future climate. Likewise, negative values of $C_{i \text { (local) }}$ indicate regions where TCs are projected to pass farther away, resulting in a decrease in TC waves in the future climate.

Figure 13 illustrates the eastward shift of TC waves. Figure 13 shows the $H_{10}$ maxima of the meridional cross section. The values are normalized by the maximum for the entire domain for each experiment, respectively. The peaks for the present climate-HPA_YS and HPA_KF-are located at $122^{\circ}$ and $128^{\circ} \mathrm{E}$, respectively. The peaks for future climates tend to shift eastward up to $139^{\circ} \mathrm{E}$ (HFA_KF_c1). And the values for future climates are smaller than present climate values over the western part of $128^{\circ} \mathrm{E}$, a result of an eastward shift in TCs.

\section{Conclusions and discussion}

We projected the future ocean wave climate based on a series of ensemble experiments with the atmospheric global climate model MRI-AGCM3.2H. The ensemble experiments of MRI-AGCM3.2H consist of four future SST ensemble experiments and three perturbed physics (PP) ensemble experiments. The present (1979-2003) and future (2075-99) wave climates were projected by WAVEWATCH III using sea surface wind data from MRI-AGCM3.2H ensemble experiments. The model performance was validated, and then the future changes in extreme wave heights and the variance among ensemble experiments were analyzed in detail. Regional frequency analysis was applied to increase the number of extreme event samples considering a homogeneous region 

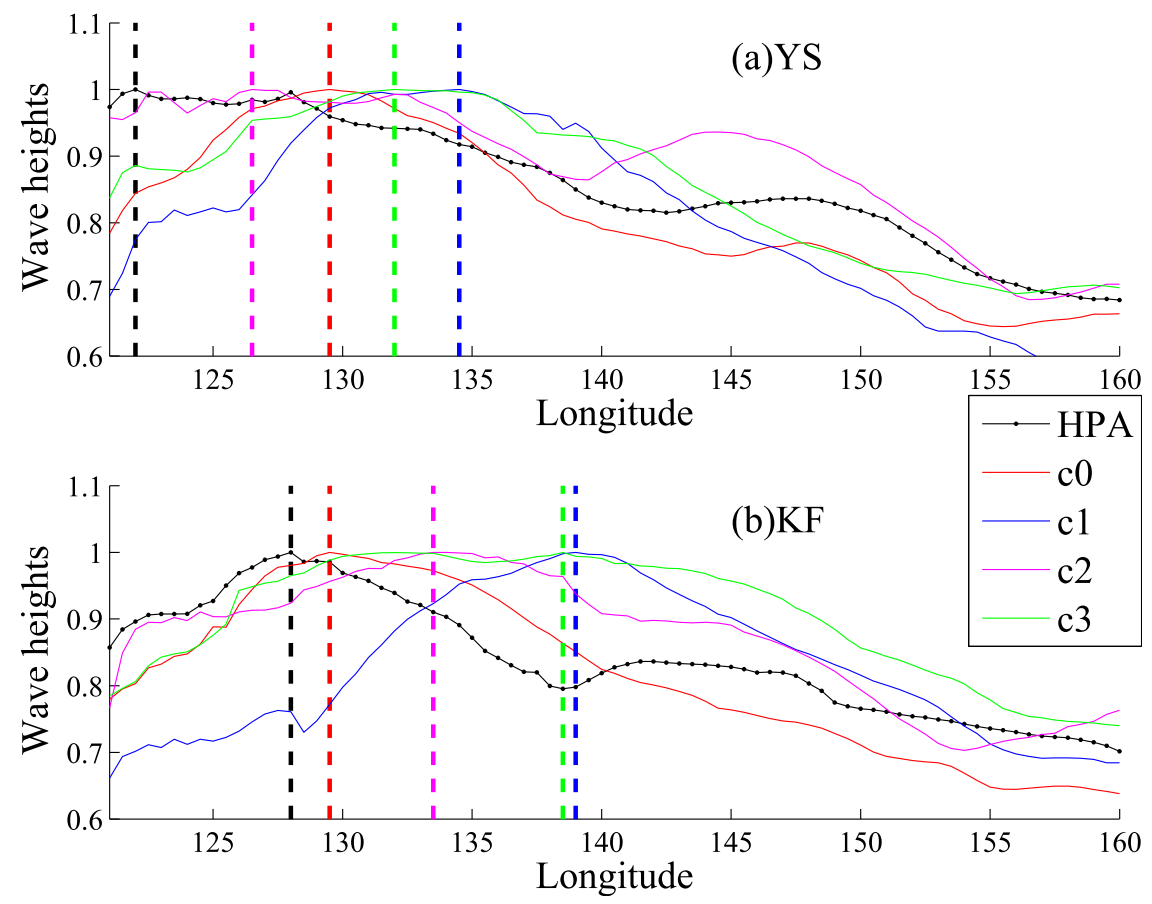

FIG. 13. Spatial distribution of $H_{10}$ in the meridional cross section. Values are normalized by the maximum value of each experiment. Dashed vertical lines indicate maximum values.

of target points. The future changes in extreme wave heights strongly depend on the model performance to simulate tropical cyclones (TCs) and their changes.

Future changes in non-TC waves on a global scale were estimated focusing on annual maxima. The ensemble mean of the future changes and standard deviation are up to about \pm 1 and $0.7 \mathrm{~m}$, respectively. The spatial distribution of future changes in extreme wave heights is similar to that of mean wave heights by our model, previous studies (e.g., IPCC 2013), and other extreme wave height analysis by Wang et al. (2014). This spatial distribution of extreme waves can be characterized as increasing over the middle-to-high latitudes in the Southern Ocean and the central North Pacific, and decreasing over the midlatitudes and the North Atlantic. From an analysis of variance of future changes, we found that the variance mainly depends on differences in physics among the PP ensemble experiments. The results depend significantly on the physics scheme of the climate model when future changes in extreme wave heights are quantitatively projected. This is the opposite for the case of mean wave changes, which depend significantly on SST difference (Shimura et al. 2015).

Future changes in TC waves over the WNP were estimated by focusing on 10-yr return wave heights. Ensemble means of the future changes and standard deviations are up to about $\pm 4(30 \%)$ and $3 \mathrm{~m}$, respectively. The spatial distribution of future changes in extreme wave heights can be qualitatively characterized by a minus and plus alternating pattern, such as decrease, increase, decrease, and increase clockwise from the southwestern part of the WNP to the southeastern region (Fig. 9a). This pattern was found to result from an eastward shift in the TC track (Fig. 12). In terms of statistical stability, hundreds of years of simulations need to be made in order to get a stable climatology of tropical cyclone characteristics over a region. However, it is also shown by previous studies that TC tracks in the WNP would shift eastward under a climate change scenario with large-scale climate change (e.g., Wu and Wang 2004; Yokoi et al. 2013; Colbert et al. 2015). Following the results of this study, estimating the TC track shift is an important component of impact assessments because a track shift can be the primary factor behind extreme wave change.

In terms of non-TC waves, future changes in mean wave heights of non-TC waves (Fig. 14a) are almost the same as those of mean wave heights (including TC and non-TC waves). The spatial distribution of future changes for mean, $H_{\mathrm{ann}}$, and $H_{1,10}$ of non-TC waves can be characterized with the same features, such as increasing over middle-to-high latitudes and decreasing over low-to-middle latitudes (Figs. 14a-d). However, the magnitude of future change of extreme wave height is larger than for the mean wave height. In the North Pacific $\left(30^{\circ}-45^{\circ} \mathrm{N}, 140^{\circ} \mathrm{W}-180^{\circ}\right)$, the future changes in 

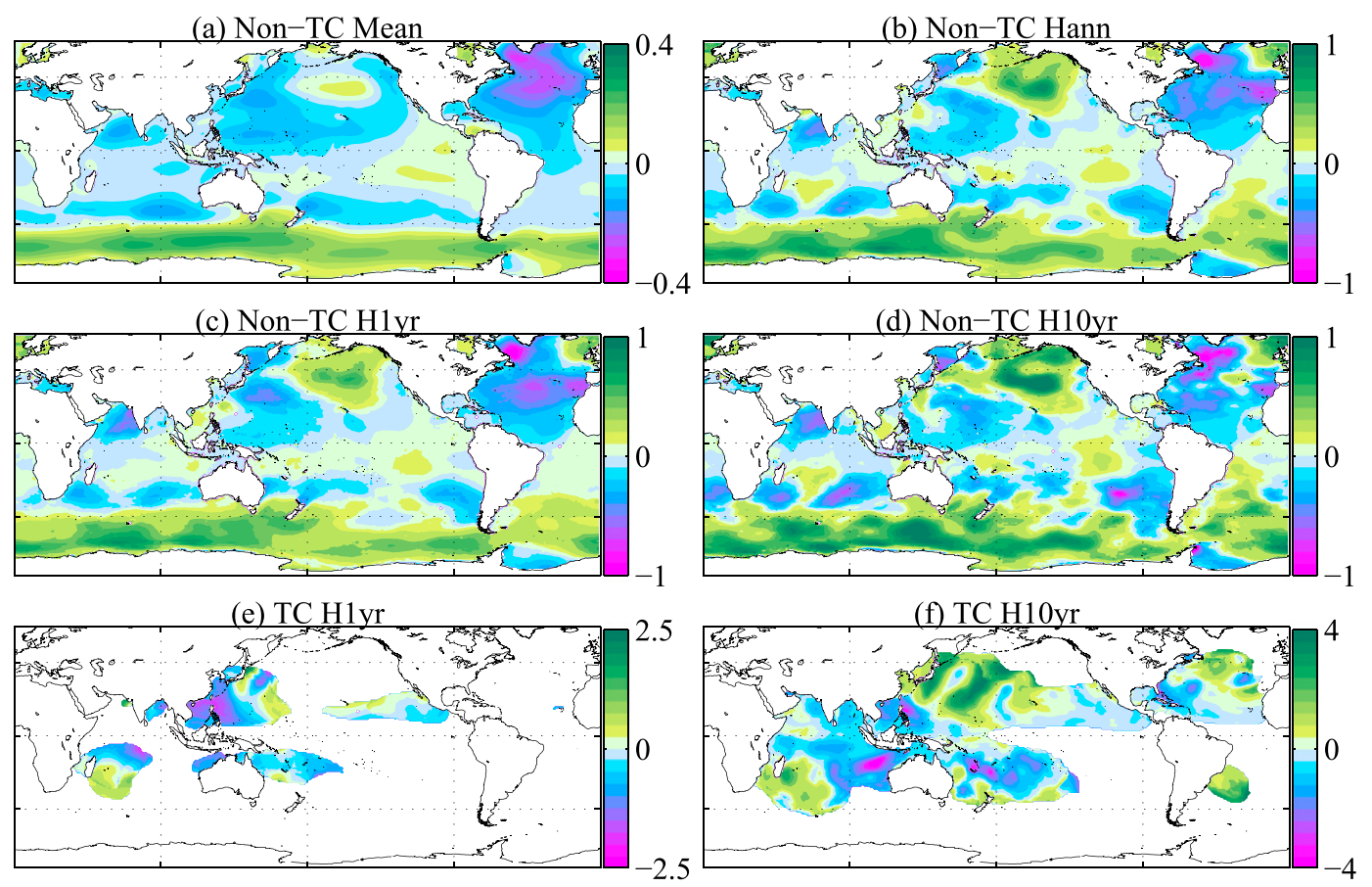

FIG. 14. Future changes in global non-TC and TC wave heights for different selections and periods (m). (a) Mean wave heights of non-TC waves, (b) $H_{\text {ann }}$ of non-TC waves, (c) $H_{1}$ of non-TC waves, (d) $H_{10}$ of non-TC waves, (e) $H_{1}$ of TC waves (colored regions indicate $\lambda \geq 1 \mathrm{TC}$ wave occurrence per year), and (f) $H_{10}$ of TC waves (colored regions indicate $\lambda \geq 0.1 \mathrm{TC}$ wave occurrence per year).

regional average of mean wave height, $H_{\mathrm{ann}}, H_{1}$, and $H_{10}$ are $+0.02,+0.49,+0.38$, and $+0.65 \mathrm{~m}$, respectively. In the North Atlantic $\left(30^{\circ}-45^{\circ} \mathrm{N}, 10^{\circ}-60^{\circ} \mathrm{W}\right)$, the future changes in regional average of mean wave height, $H_{\text {ann }}$, $H_{1}$, and $H_{10}$ are $-0.20,-0.44,-0.45$, and $-0.23 \mathrm{~m}$, respectively. And, over the Southern Ocean $\left(45^{\circ}-60^{\circ} \mathrm{S}\right)$, the future changes in the regional average of mean wave height, $H_{\mathrm{ann}}, H_{1}$, and $H_{10}$ are $+0.12,+0.35,+0.33$, and $+0.40 \mathrm{~m}$, respectively.

Global TC waves tend to decrease over the lower latitudes and increase over the higher-latitude regions (Figs. 14e,f). The future change in $H_{1}$ (Fig. 14e) is dominated by the effect of TC wave frequency change $C_{f}$ as discussed in section $4 \mathrm{~b}$. The value of $H_{10}$ in the North Atlantic decreases over the southwestern regions and increases over the northeastern regions, which is similar to the result in the WNP, characterized as an eastward shift of TC (and TC waves). The value of $H_{10}$ in the south Indian Ocean can be characterized as increasing over the region southeast of Madagascar and decreasing over lower latitudes and the eastern part of the ocean basin. The value of $H_{10}$ in the South Pacific shows a reduction over nearly the entire region. Fan et al. (2013) also showed robust decreases of extreme wave heights in the South Pacific, which is attributed to a decrease in TC frequency.
Finally, we emphasize the important points for extreme wave climate projection.

- The GCM performance needs to be validated with consideration toward the dominant extreme phenomena that cause extreme waves. Caution should be used in interpreting the future changes in extreme wave climate from a GCM without such a consideration.

- Extreme wave changes are determined by mixed effects that occur from changes in several characteristics of extreme phenomena, such as location shift, intensification (or weakening), increase (or decrease) in frequency, etc.

- Furthermore, the ratio of contributing factors behind extreme waves will change and vary depending on the target time frame or design context, for example, whether the return period for wave heights is 1 and $10 \mathrm{yr}$ as indicated in the differences between Figs. 10 and 11.

Acknowledgments. The authors were supported by the Japan Society for the Promotion of Science (JSPS) Fellowships for Young Scientists and Grant-in-Aid for JSPS Fellows. This research was supported under the SOUSEI Program by the Ministry of Education, Culture, Sports, Science, and Technology (MEXT). 


\section{REFERENCES}

Ardhuin, F., and Coauthors, 2010: Semiempirical dissipation source functions for ocean waves. Part I: Definition, calibration, and validation. J. Phys. Oceanogr., 40, 1917-1941, doi:10.1175/ 2010JPO4324.1.

—, J. Hanafin, Y. Quilfen, B. Chapron, P. Queffeulou, M. Obrebski, J. Sienkiewicz, and D. Vandemark, 2011: Calibration of the "IOWAGA" global wave hindcast (1991-2011) using ECMWF and CFSR winds. Proc. 12th Int. Workshop on Wave Hindcasting and Forecasting/Third Coastal Hazard Symp., Kohala Coast, HI, JCOMM, I17. [Available online at http://www.jcomm.info/images/stories/2011/12thWaves/Papers/ ardhuin_etal_hindcast_whf2011.pdf.]

Bromirski, P. D., and J. P. Kossin, 2008: Increasing hurricane wave power along the U.S. Atlantic and Gulf Coasts. J. Geophys. Res., 113, C07012, doi:10.1029/2007JC004706.

— , D. R. Cayan, J. Helly, and P. Wittmann, 2013: Wave power variability and trends across the North Pacific. J. Geophys. Res. Oceans, 118, 6329-6348, doi:10.1002/2013JC009189.

Chao, Y. Y., and H. L. Tolman, 2010: Performance of NCEP regional wave models in predicting peak sea states during the 2005 North Atlantic hurricane season. Wea. Forecasting, 25, 1543-1567, doi:10.1175/2010WAF2222309.1.

Colbert, A. J., B. J. Soden, and B. P. Kirtman, 2015: The impact of natural and anthropogenic climate change on western North Pacific tropical cyclone tracks. J. Climate, 28, 1806-1823, doi:10.1175/JCLI-D-14-00100.1.

Cooley, D., D. Nychka, and P. Naveau, 2007: Bayesian spatial modeling of extreme precipitation return levels. J. Amer. Stat. Assoc., 102, 824-840, doi:10.1198/016214506000000780.

Dee, D., and Coauthors, 2011: The ERA-Interim reanalysis: Configuration and performance of the data assimilation system. Quart. J. Roy. Meteor. Soc., 137, 553-597, doi:10.1002/qj.828.

Emanuel, K., 2005: Increasing destructiveness of tropical cyclones over the past 30 years. Nature, 436, 686-688, doi:10.1038/ nature 03906 .

Endo, H., A. Kitoh, T. Ose, R. Mizuta, and S. Kusunoki, 2012: Future changes and uncertainties in Asian precipitation simulated by multiphysics and multi-sea surface temperature ensemble experiments with high-resolution Meteorological Research Institute atmospheric general circulation models (MRI-AGCMs). J. Geophys. Res., 117, D16118, doi:10.1029/ 2012JD017874.

Fan, Y., I. M. Held, S.-J. Lin, and X. L. Wang, 2013: Ocean warming effect on surface gravity wave climate change for the end of the 21st century. J. Climate, 26, 6046-6066, doi:10.1175/ JCLI-D-12-00410.1.

Graham, N. E., and H. F. Diaz, 2001: Evidence for intensification of North Pacific winter cyclones since 1948. Bull. Amer. Meteor. Soc., 82, 1869-1893, doi:10.1175/1520-0477(2001)082<1869: EFIONP $>2.3 . \mathrm{CO} ; 2$.

Hemer, M. A., 2010: Historical trends in Southern Ocean storminess: Long-term variability of extreme wave heights at Cape Sorell, Tasmania. Geophys. Res. Lett., 37, L18601, doi:10.1029/ 2010 GL044595.

—, Y. Fan, N. Mori, A. Semedo, and X. Wang, 2013: Projected changes in wave climate from a multi-model ensemble. Nat. Climate Change, 3, 471-476, doi:10.1038/nclimate1791.

Hosking, J., and J. Wallis, 1997: Regional Frequency Analysis. Cambridge University Press, 244 pp.

IPCC, 2013: Climate Change 2013: The Physical Science Basis. Cambridge University Press, 1535 pp., doi:10.1017/CBO9781107415324.
Kobayashi, S., and Coauthors, 2015: The JRA-55 Reanalysis: General specifications and basic characteristics. J. Meteor. Soc. Japan, 93, 5-48, doi:10.2151/jmsj.2015-001.

Komar, P. D., and J. C. Allan, 2008: Increasing hurricanegenerated wave heights along the U.S. East Coast and their climate controls. J. Coastal Res., 24, 479-488, doi:10.2112/ 07-0894.1.

Manganello, J. V., and Coauthors, 2012: Tropical cyclone climatology in a 10-km global atmospheric GCM: Toward weatherresolving climate modeling. J. Climate, 25, 3867-3893, doi:10.1175/JCLI-D-11-00346.1.

Meehl, G. A., C. Covey, K. E. Taylor, T. Delworth, R. J. Stouffer, M. Latif, B. McAvaney, and J. F. Mitchell, 2007: The WCRP CMIP3 multimodel dataset: A new era in climate change research. Bull. Amer. Meteor. Soc., 88, 1383-1394, doi:10.1175/ BAMS-88-9-1383.

Menéndez, M., F. Méndez, I. Losada, and N. Graham, 2008: Variability of extreme wave heights in the northeast Pacific Ocean based on buoy measurements. Geophys. Res. Lett., 35, L22607, doi:10.1029/2008GL035394.

Mizuta, R., and Coauthors, 2012: Climate simulations using MRIAGCM3.2 with 20-km grid. J. Meteor. Soc. Japan, 90A, 233258, doi:10.2151/jmsj.2012-A12.

Moore, L. J., D. E. McNamara, A. B. Murray, and O. Brenner, 2013: Observed changes in hurricane-driven waves explain the dynamics of modern cuspate shorelines. Geophys. Res. Lett., 40, 5867-5871, doi:10.1002/2013GL057311.

Mori, N., T. Yasuda, H. Mase, T. Tom, and Y. Oku, 2010: Projection of extreme wave climate change under global warming. Hydrol. Res. Lett., 4, 15-19, doi:10.3178/hrl.4.15.

Murakami, H., 2014: Tropical cyclones in reanalysis data sets. Geophys. Res. Lett., 41, 2133-2141, doi:10.1002/2014GL059519.

- and M. Sugi, 2010: Effect of model resolution on tropical cyclone climate projections. SOLA, 6, 73-76, doi:10.2151/sola.2010-019.

, R. Mizuta, and E. Shindo, 2012: Future changes in tropical cyclone activity projected by multi-physics and multi-SST ensemble experiments using the 60-km-mesh MRI-AGCM. Climate Dyn., 39, 2569-2584, doi:10.1007/s00382-011-1223-x.

Ruggiero, P., P. D. Komar, and J. C. Allan, 2010: Increasing wave heights and extreme value projections: The wave climate of the U.S. Pacific Northwest. Coastal Eng., 57, 539-552, doi:10.1016/j.coastaleng.2009.12.005.

Sasaki, W., S. Iwasaki, T. Matsuura, and S. Iizuka, 2005: Recent increase in summertime extreme wave heights in the western North Pacific. Geophys. Res. Lett., 32, L15607, doi:10.1029/ 2005 GL023722.

Shimura, T., N. Mori, and H. Mase, 2015: Future projection of ocean wave climate: Analysis of SST impacts on wave climate changes in the western North Pacific. J. Climate, 28, 31713190, doi:10.1175/JCLI-D-14-00187.1.

Slott, J. M., A. B. Murray, A. D. Ashton, and T. J. Crowley, 2006: Coastline responses to changing storm patterns. Geophys. Res. Lett., 33, L18404, doi:10.1029/2006GL027445.

Sterl, A., and S. Caires, 2005: Climatology, variability and extrema of ocean waves: The web-based KNMI/ERA-40 wave atlas. Int. J. Climatol., 25, 963-977, doi:10.1002/joc.1175.

Stopa, J. E., and K. F. Cheung, 2014: Intercomparison of wind and wave data from the ECMWF Reanalysis Interim and the NCEP Climate Forecast System Reanalysis. Ocean Modell., 75, 65-83, doi:10.1016/j.ocemod.2013.12.006.

Taylor, K. E., R. J. Stouffer, and G. A. Meehl, 2012: An overview of CMIP5 and the experiment design. Bull. Amer. Meteor. Soc., 93, 485-498, doi:10.1175/BAMS-D-11-00094.1. 
Tolman, H. L., 2009: User manual and system documentation of WAVEWATCH III version 3.14. MMAB Tech. Note 276, 220 pp. [Available online at http://polar.ncep.noaa.gov/mmab/ papers/tn276/MMAB_276.pdf.]

, 2014: User manual and system documentation of WAVEWATCH III version 4.18. MMAB Tech. Note, 311 pp. [Available online at http://polar.ncep.noaa.gov/waves/ wavewatch/manual.v4.18.pdf.]

— wind wave model. J. Phys. Oceanogr., 26, 2497-2518, doi:10.1175/ 1520-0485(1996)026<2497:STIATG $>2.0 . C O ; 2$.

_— , and J.-H. G. Alves, 2005: Numerical modeling of wind waves generated by tropical cyclones using moving grids. Ocean Modell., 9, 305-323, doi:10.1016/j.ocemod.2004.09.003.

von Storch, H., and F. Zwiers, 1999: Statistical Analysis in Climate Research. Cambridge University Press, 484 pp.

Wang, X. L., and V. R. Swail, 2001: Changes of extreme wave heights in Northern Hemisphere oceans and related atmospheric circulation regimes. J. Climate, 14, 2204-2221, doi:10.1175/ 1520-0442(2001)014<2204:COEWHI > 2.0.CO;2.

_ and —-, 2006: Climate change signal and uncertainty in projections of ocean wave heights. Climate Dyn., 26, 109-126, doi:10.1007/s00382-005-0080-x.

- — , F. W. Zwiers, X. Zhang, and Y. Feng, 2009: Detection of external influence on trends of atmospheric storminess and northern oceans wave heights. Climate Dyn., 32, 189-203, doi:10.1007/s00382-008-0442-2.

—, Y. Feng, and V. R. Swail, 2014: Changes in global ocean wave heights as projected using multimodel CMIP5 simulations. Geophys. Res. Lett., 41, 1026-1034, doi:10.1002/2013GL058650.

Wu, L., and B. Wang, 2004: Assessing impacts of global warming on tropical cyclone tracks. J. Climate, 17, 1686-1698, doi:10.1175/ 1520-0442(2004)017<1686:AIOGWO>2.0.CO;2.

- _ - and S. Geng, 2005: Growing typhoon influence on East Asia. Geophys. Res. Lett., 32, L18703, doi:10.1029/ 2005 GL022937.

Yokoi, S., Y. Takayabu, and H. Murakami, 2013: Attribution of projected future changes in tropical cyclone passage frequency over the western North Pacific. J. Climate, 26, 4096-4111, doi:10.1175/JCLI-D-12-00218.1.

Yong, H., Y. Baoshu, W. Perrie, and H. Yijun, 2008: Responses of summertime extreme wave heights to local climate variations in the East China Sea. J. Geophys. Res., 113, C09031, doi:10.1029/2008JC004732.

Young, I., S. Zieger, and A. Babanin, 2011: Global trends in wind speed and wave height. Science, 332, 451-455, doi:10.1126/ science.1197219.

— J. Vinoth, S. Zieger, and A. Babanin, 2012: Investigation of trends in extreme value wave height and wind speed. J. Geophys. Res., 117, C00J06, doi:10.1029/2011JC007753. 